\title{
The Electronic Properties of the Silver Clusters in Gas Phase and Water
}

\author{
Mariana Virginia Popa \\ Electronic and Telecomunication, Autonomous University of the Hidalgo State, Mexico
}

Email address:

virginia_popa@yahoo.com.mx,pmarianavirginia@yahoo.com

\section{To cite this article:}

Mariana Virginia Popa. The Electronic Properties of the Silver Clusters in Gas Phase and Water. International Journal of Computational and Theoretical Chemistry. Special Issue: Electronic Proprieties in Computational Chemistry. Vol. 3, No. 3-1, 2015, pp. $36-57$.

doi: $10.11648 /$ j.ijctc.s. 2015030301.13

\begin{abstract}
En this article are presented the theorics work for clarify the structure of all silver cluster in gas phase and water and are compareted the results with experimental data for see which levels of theory describe better the propriety of the silver cluster. Are calculated different value of the bond, ionization potentials and frequencies, electron affinities and binding energy method employed ab initio and relativystic bases. Are optimization with the following levels of theorie: HF/LANL1MB, HF/LANL2MB, HF/LANL2DZ, B3LYP/LANL1MB, B3LYP/LANL2MB, B3LYP/LANL2DZ, MP2/LANL2DZ, DFT/PBE/SDD and DFT/PBE/3-21G**.
\end{abstract}

Keywords: Silver, Relativystic Effects, Metal Clusters, Silver Cluster in Water

\section{Introduction}

In the past two decade has been showing great interest for explanation the electronics proprieties of silver cluster with the nanometre dimensión due to the proprieties who to exhibit the cluster generally, are diferent of the solid state $[1,2,3]$ and molecular [4].

The study of the structure of the clusters of dimension nano to require to compare the date of the diferents experiments and theorie.

The extraordinary proprieties of silver clusters to give a reason a much investigator to realice the worcks in photography, catalisis and news materials of electronic $[5,6-$ $14]$.

Has been moderate that the relativistic effects influe in the electronic proprieties, so how in the geometry of the metals of transition so that gold, cooper and silver [15]. The orbital $6 \mathrm{~s}$ in gold to contract for the relativistic effect [15].

In [16] has been make the studie with ion of silver with espectroscopy of mass. The neutral clusters has been obtained bombardment sheet of metal with ion Xe. Has been regarde who the distribution of masa similar for negative and positive clusters. Has been analyze the structure of anion cluster $\operatorname{Ag}_{n}(n=1-9)$ useful the electronic espectrofotometry with gas He [17]. With nuclear magnetic espectroscopy of resonance and ultraviolet absorcion espectroscopy has been evidence the Jahn-Teller effect for $\mathrm{Ag}_{3}[18,19]$. Has been employed optic espectroscopy in the Ar matrix to characterize $\mathrm{Ag}_{4}$ and has been evidence two isomerous stables $D_{2 h}$ and $C_{2 V}$ with the difference between isomerous $0 f$ $0.2 \mathrm{eV}$ [20]. Employed the electronic spin resonance has been evidence the dimer, trimeros an pentamer wirh the JahnTeller effect for the silver clusters [21,22].

With the generator of $\mathrm{N}_{2}$ laser, the vertical ionization potentials for $\operatorname{Ag}_{n}(n<100)$ has been study $[23,24]$.

The fotoelectronic espectroscopy $[25,26]$ is a powerful technical for to study of electronic structure of metalic clusters and an very good method for adiabatic electronic affinity. The anionic clusters are separated with an massa espectromettre.

Has been evidence the alternate of the values for vertical electronic affinity with the variation even/odd (until 40 atoms) of silver used the fotoelectronic spectra in UV with He gas and laser with energy of the photon $6.4 \mathrm{y} 7.9 \mathrm{eV}[27,28]$.

The frequency of the ${ }^{2} \mathrm{~B}_{2}$ and ${ }^{2} \mathrm{~A}_{1}$ has been evidence employed the optic espectra emision with $\mathrm{Ag}_{3}$ evaporation at low pressure in He (100Torr) [29].

With the fotoelectronic espectra has been evidence the frequencies of the silver cluster $\leq 70$ atoms [30]. Employed the optic resonancie absorption for $\mathrm{Ag}_{4}^{+}$has been evidence the fotofragmentation of anion cluster [31].

In the literature to attain various works with $\mathrm{Ag}$ clusters $[32,40]$. 
In the experimental review silver clusters were prepared in an argon matrix by using high-temperature matrix preparation, [70].

In [71] silver ions are sput-tered from a silver target using an intense and high-energy xenon-ion beam typically $10 \mathrm{~mA}$, $24 \mathrm{keV}$. A development of the finite difference method is used to compute atomic-cluster absorption spectra. The spectra is compared with recent high-precision measurements of the Xray mass absorption coefficient of silver in the X-ray absorption fine structure región, [72].

The degeneracy of the ground electronic state can lead to Jahn-Teller distortion along the e' bending coordinate. This lowers the symmetry from $\mathrm{D}_{3 \mathrm{~h}}$, to $\mathrm{C}_{2 \mathrm{v}}$ and correspondingly, the ${ }^{2} \mathrm{E}$ ' state is resolved into ${ }^{2} \mathrm{~B}_{2}$ (obtuse isosceles triangle) and ${ }^{2} \mathrm{~A}_{1}$ (acute isosceles triangle) states.

The three ${ }^{2} \mathrm{~B}_{2}$ extrema are equivalent global minima or saddle points in the ground state potential surface while the three equivalent ${ }^{2} \mathrm{~A}_{1}$ extrema are saddle points or minima along the pseudorotation path. The $\mathrm{D}_{3 \mathrm{~h}}$ equilateral triangle geometry occurs at a cusp on the surface.

The optical-absorption spectra of small mass-selected AgN clusters $(\mathrm{N}=2-21)$ embedded in solid argón are mesured in the energy range 2.5-6.2 eV. Investigation of a continous range of cluster sizes reveals the size development of the photoabsorption behavior, [73]. Brifly, silver ions are sputtered from a metal target using an intense, high-energy (typically $7 \mathrm{~mA}, 23 \mathrm{KeV}$ ) xenon-ion beam, [73].The photoionization mass spectrum obtained and vertical ionization potentials plotted in [74]. Photoelectron spectra of $\mathrm{Ag}_{\mathrm{n}}$ - clusters with $\mathrm{n}=1-21$ recorded at different photon energies $(\mathrm{h} \gamma=54.025,4.66,5.0$, and $6.424 \mathrm{eV})$ are presented in $[75]$.

In [76] are investigated mass distributions of negative cluster ions of copper $(\mathrm{Cu})_{\mathrm{n}}^{-}$, silver $(\mathrm{Ag}) \mathrm{n}^{-}$, and gold $(\mathrm{Au})_{\mathrm{n}}{ }^{-}$, obtained by, the bombardment of metal sheets with Xe ions were investigated up to cluster size $n=250$ and were compared with those of the positive cluster ions.

A continuous flow cryostat was used for these experiments. Temperatures above $3.5 \mathrm{~K}$ could be adjusted continuously and were measured using a calibrated carbon resistor and a vapour pressure thermometer, [77]. The reference [78] are employed photoelectron spectroscopy for negative ion $\mathrm{Cu}_{\mathrm{n}}{ }^{-}$, $\mathrm{Ag}_{\mathrm{n}}{ }^{-}(\mathrm{n}=1-10)$, and $\mathrm{Au}_{\mathrm{n}}{ }^{-}(\mathrm{n}=1-5)$ are presented for electron binding energies up to $3.35 \mathrm{eV}$ at an instrumental resolution of 6-9 meV. The metal cluster anions are prepared in a flowing ion source with a cold cathode de discharge.

Stable nanoparticle colloids of silver were obtained by irradiation of aqueous-alcoholic solutions of $\mathrm{AgNO}_{3}$ in the presence of mesoporous $\mathrm{SiO}_{2}$ powder and films modified with benzophenone $\left(\mathrm{BP} / \mathrm{SiO}_{2}\right),[79]$.

\section{Results and Discussion}

To introduce the electronic effects of correlation with B3LYP and B3PW91 functionals and relativistic effect with LANL2DZ and LANL2MB bases for $\mathrm{Ag}_{2}$ are report the studys in reference [36], with BPW91 and SVWN IIa LANL2DZ base, the mistake for geometry are 3-4\% y for frecuencies $6-8 \%$. Also are reach the difference of the proprieties of $\mathrm{Ag}_{2}$ above mentionen, with MP2 and $\mathrm{S}$ VWN+Beke-Perdew functionals [37]. To be able that $\mathrm{Ag}_{2}$ the distances are satisfy compared with $2.53 \AA$ experimetal data.

Fort the three atoms clusters has been realice divers study for top put in evidence the Jahn-Teller efecto and to calculation the electronics affinity [41-43]. Employed CC has been reported the date for silver clusters with 4,5 and 6 atoms [44].

\section{Distance in Clusters}

\subsection{Neutral Dimers, Anions and Cations}

How are to observe in the Fig. 1 (Ia) [80], the distancefor neutral cluster of two atoms obtained with HF/LANL1MB is the $2.91 \AA$. Employed the HF/LANL2MB method the distance are to contract $0.1 \AA$, see Fig. 2 (Ia) [80]. With HF/LANL2DZ method has been obtained $2.73 \AA$ for the neutral cluster with two atoms, see Fig. 3 (Ia) [80], less who in the two events up mentioned. The difference of $0.18 \AA$ between the cluster optimized with LANL2DZ and LANL1MB, who introduce the relativistic effects are possible for the 19 electrons in the valence layer employed LANLEDZ base, compared with 11 electrons introducted with LANL1MB base and the primitive employed [45, 46].

Not with standing this values are distant of the experimental data 2.5303(2) $\AA$, see 39].

The dimer structure optimized are to present in the Figure of 1 at 9. The distance are in $\AA$.

$$
\begin{aligned}
& \text { a)Ia } \overbrace{}^{2.91} \mathrm{~b}) \mathrm{Ib} \overbrace{}^{3.27} \mathrm{c}) \mathrm{Ic} \mathrm{Q}^{3.37} \\
& \mathrm{D}_{\infty h}, \sum_{g}^{+},(0.00,0.45) \mathrm{D}_{\infty h},{ }^{2} \sum_{u}^{+},(0.00,0.57) \mathrm{D}_{\infty h},{ }^{2} \sum_{g}^{+},(0.00,0.42) \\
& \text { A)Ia } Q^{3.04} \bigcirc \\
& \mathrm{D}_{\infty h}, \sum_{g}^{+}
\end{aligned}
$$

Fig. 1. The structure of dimer clusters with HF/LANL1MB: a) neutral; b) anions; c) cations. Between parenthesis are reported the relative energy, $\triangle E$, (eV), and biding energy for atom ( $\mathrm{eV})$. A) for neutral in water. 


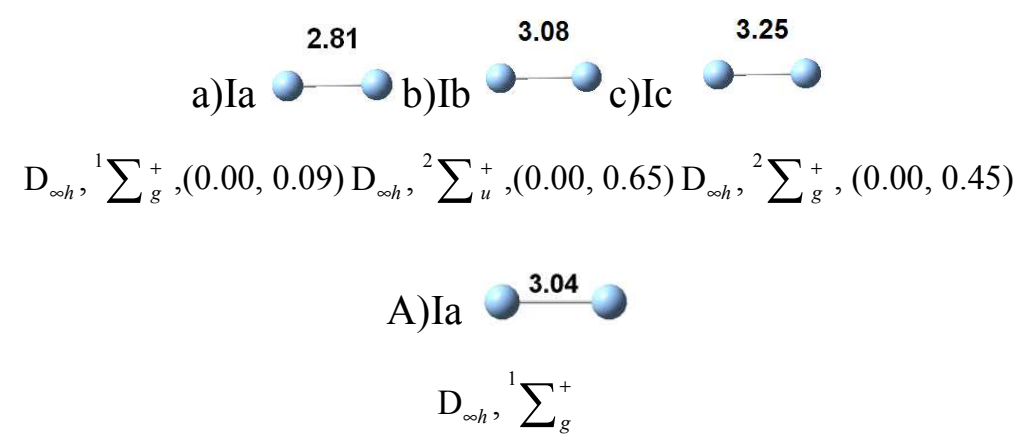

Fig. 2. The structure of dimer clusters with HF/LANL2MB: a) neutral; b) anions; c) cations. Between parenthesis are reported the relative energy, $\triangle E$, (eV), and biding energy for atom (eV). A) for neutral in water.

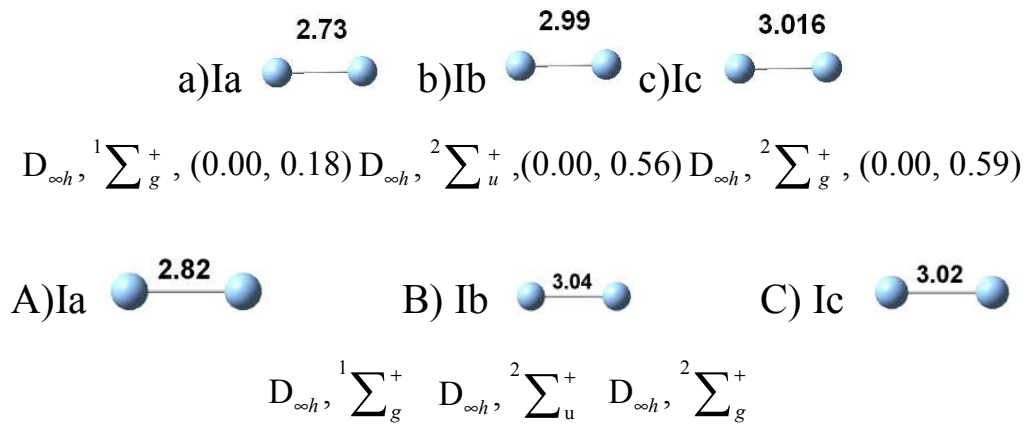

Fig. 3. The structure of dimer clusters with HF/LANL2DZ: a) neutral; b) anions; c) cations. Between parenthesis are reported the relative energy, $\triangle E$, (eV), and biding energy for atom (eV). A), B) and C) for neutral anions, cations in water.

$$
\begin{aligned}
& \text { a) Ia } \overbrace{}^{2.87} \mathrm{~b}) \mathrm{Ib} \overbrace{}^{3.19} \mathrm{c}) \mathrm{Ic} \overbrace{}^{3.32} \\
& \mathrm{D}_{\infty h},{ }^{1} \sum_{g}^{+},(0.00,0.45) \mathrm{D}_{\infty h},{ }^{2} \sum_{u}^{+},(0.00,0.62) \mathrm{D}_{\infty h},{ }^{2} \sum_{g}^{+},(0.00,0.53) \\
& \text { A)Ia } 0^{2.93} \bigcirc \text { C) Ic } 0^{3.08} \\
& \mathrm{D}_{\infty h}, \sum_{g}^{+} \mathrm{D}_{\infty h}, \sum_{g}^{+}
\end{aligned}
$$

Fig. 4. The structure of dimer clusters with B3LYP/LANL1MB: a) neutral; b) anions; c) cations. Between parenthesis are reported the relative energy, $\triangle E$, (eV), and bidin energy for atom (eV). .). A), B) and C) for neutral anions, cations in water.

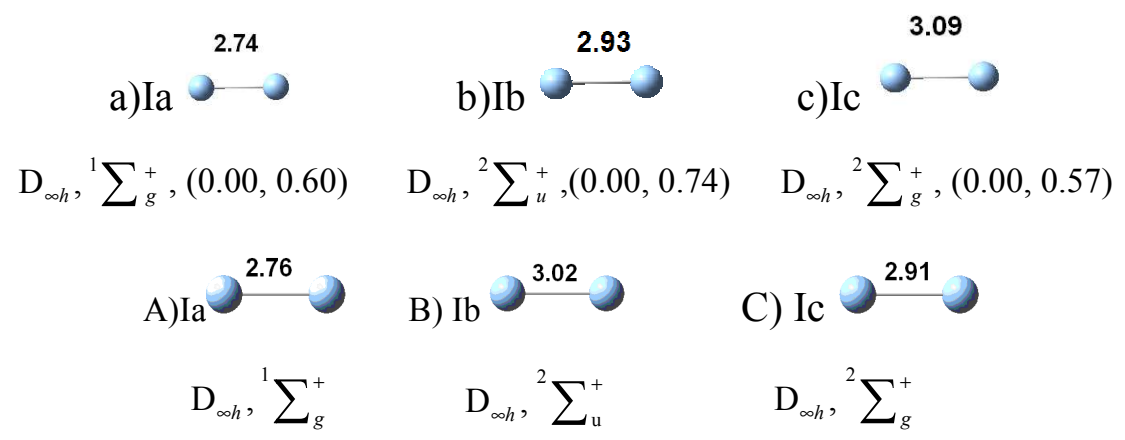

Fig. 5. The structure of dimer clusters with B3LYP/LANL2MB: a) neutral; b) anions; c) cations. Between parenthesis are reported the relative energy, $\triangle E$, (eV), and biding energy for atom (eV). ). A), B) and C) for neutral anions, cations in water. 


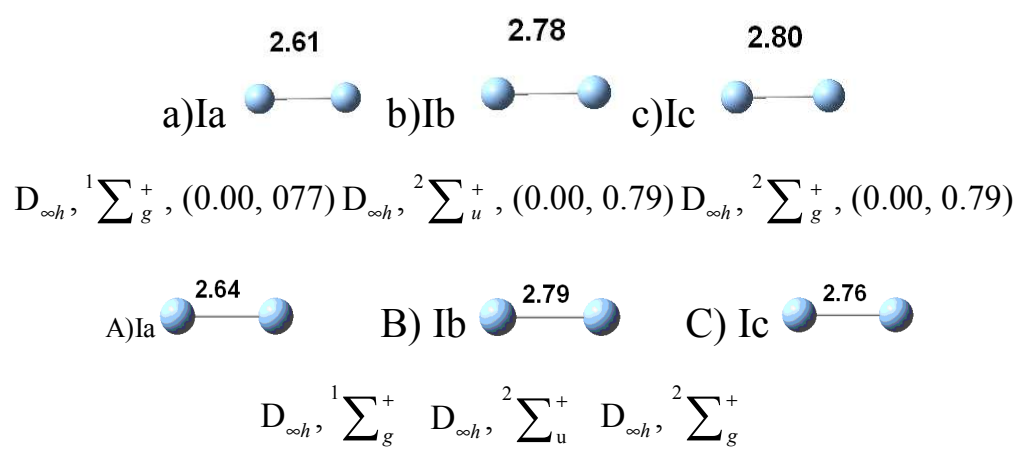

Fig. 6. The structure of dimer clusters with B3LYP/LANL2DZ: a) neutral; b) anions; c) cations. Between parenthesis are reported the relative energy, $\triangle E$, (eV), and biding energy for atom ( $(\mathrm{V})$. ). A), B) and C) for neutral anions, cations in water.

$$
\begin{gathered}
\text { a)Ia } \\
\mathrm{D}_{\infty h},{ }^{1} \sum_{g}^{+},(0.00 .0 .59) \mathrm{D}_{\infty h},{ }^{2} \sum_{u}^{+},(0.00,0.67) \mathrm{D}_{\infty h},{ }^{2} \sum_{g}^{+},(0.00,0.70)
\end{gathered}
$$

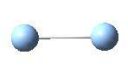

Fig. 7. The structure of dimer clusters with MP2/LANL2DZ: a) neutral; b) anions; c) cations. Between parenthesis are reported the relative energy, $\triangle E$, (eV), and biding energy for atom $(\mathrm{eV})$

$$
\begin{aligned}
& \begin{array}{lll}
2.57 & 2.71 & 2.74
\end{array} \\
& \text { a)Ia b)Ib } \bigcirc \text { c)Ic } \\
& \mathrm{D}_{\infty h},{ }^{1} \sum_{g}^{+},(0.00,0.88) \mathrm{D}_{\infty h},{ }^{2} \sum_{u}^{+},(0.00,0.74) \mathrm{D}_{\infty h},{ }^{2} \sum_{g}^{+},(0.00,0.90)
\end{aligned}
$$

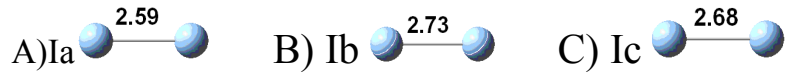

$$
\begin{aligned}
& \mathrm{D}_{\infty h}, \sum_{g}^{+} \mathrm{D}_{\infty h}, \sum_{\mathrm{u}}^{+} \mathrm{D}_{\infty h}, \sum_{g}^{+}
\end{aligned}
$$

Fig. 8. The structure of dimer clusters with PBE/SDD: a) neutral; b) anions; c) cations. Between parenthesis are reported the relative energy, $\triangle E$, (eV), and biding energy for atom (eV). ). A), B) and C) for neutral anions, cations in water.

$$
\begin{aligned}
& \text { a)Ia } e^{2.53} \text { b)Ib } 0^{2.60} \text { c)Ic } e^{2.67} \\
& \mathrm{D}_{\infty h}, \sum_{g}^{+},(0.00,1.14) \mathrm{D}_{\infty h},{ }^{2} \sum_{u}^{+},(0.00,1.07) \mathrm{D}_{\infty h},{ }^{2} \sum_{g}^{+},(0.00,1.08)
\end{aligned}
$$

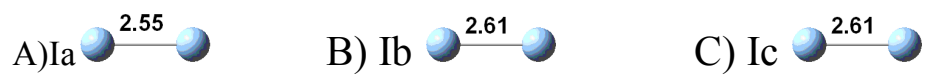

$$
\begin{aligned}
& \mathrm{D}_{\infty h}, \sum_{g}^{+} \mathrm{D}_{\infty h}, \sum_{\mathrm{u}}^{+} \mathrm{D}_{\infty h},{ }^{2} \sum_{g}^{+}
\end{aligned}
$$

Fig. 9. The structure of dimer clusters with PBE/3-21G**: a) neutral; b) anions; c) cations. Between parenthesis are reported the relative energy, $\triangle E$, (eV), and biding energy for atom (eV). ). A), B) and C) for neutral anions, cations in water.

For the dimer anion and cation calculated with HF/LANL1MB has been obtained $3.27 \AA$ y $3.37 \AA$, see Fig. 1 (Ib y Ic); the cation cluster to designa an greater distance beteen of the atoms who anion, for the repulsion beteen the nucleos.

The distance beteen the atoms for anion cluster is greater who neutral cluster for the core electrons. Of this manner the electrons of the valence mantle make larger electronic density. Employed DFT with B3LYP the distance beteen the atoms in neutral cluster lower in the following order LANL1MB > LANL2MB > LANL2DZ, see Fig.4 (Ia), Fig. 5 (Ia) y Fig. 6 (Ia). The $2.61 \AA$ obtained with the DFT/B3LYP/LANL2DZ level is equal who reported in [47] but greater who employed B3P86/LANL2DZ (2.576 $\AA$ ) and B3PW91/LANL2DZ (2.589 A) [48]. With SVWN (LSDA)/LANL2DZ and SVWN5/LANL2DZ has been 
obtained 2.501 y $2.508 \AA[48]$, underestimate with experimental data 2.5303(2) $\AA$ [49]. Fort he neutral cluster of two atoms to employed MP2/LANLEDZ, are obtained $2.68 \AA$ identicaly with [39] and with difference of $0.01 \AA$ obtained with CCSD [39]. In water are obtained different value when are posible the ionization of anion, catión silver cluster.

For the anion and cation dimer, with the same level, has been obtained $2.91 \AA$ y $2.82 \AA$, similar in the [39].

The value obtained for $\mathrm{Ag}_{2}$ employed PBE/SDD is greater who $0.04 \AA$ of the experimental value and minor with $0.04 \AA$ who obtained with B3LYP/LANL2DZ and 0.01 $\AA$ that the value obtained with G96LYP/SDD [39]. In barter with DFT/PBE/3-21G** level are obtained $2.531 \AA$ similar with the experimental data [49].

Fort he two atoms for anion with the DFT/PBE/3-21G** level has been attained $2.60 \AA$ verynear of the experimental data $2.62 \AA[50]$.

For geometrically to describe the silver dimer cluster I employed PBE and 3-21G**.

\subsection{Neutral Trimer, Anions and Cations}

For the trimer are not experimental data above the distance of the atoms in clusters, for this reason I present the smallests and sadle point in the potential energy surface for neutral clusters, with B3LYP and LANL1MB, LANL2MB y LANL2DZ bases, with MP2, and DFT/PBE/SDD y DFT/PBE/3-21G**.

Experimentally, [37, 41, 42, 51-55], and employed the thoeretic jobs $[32,44,56,57]$ has been see the Jahn-Teller efects, more for the $D_{3 h}$ structure and are separate in smart, optuse triangle and to draw lines structure [25].

In ${ }^{2} E^{\prime}$ the electronic configuration is $\left(a_{1}^{\prime}\right)^{2}\left(e^{\prime}\right)^{1}$ where $a_{1}^{\prime}$ are the combination of three $s$ AOs and $e^{\prime}$ is the orbital of the not connection double binding [57].

The ${ }^{2} B_{2}$ is always more low in energie that ${ }^{2} A_{1}$, already who the apex atoms mix the caracter of the p orbital and the bonding augmented [58]. The autors of the [19] and [40], employed ab initio han been obtained who $\left(\sigma_{g}\right)^{2}\left(\sigma_{u}\right)^{1}$ is less estable with $0.05 \mathrm{eV}$ who ${ }^{2} E^{\prime}$. The molecular orbitals $\sigma_{g}, \sigma_{u} 2 \sigma_{g}$ and as combination of 3 orbitals s of $\mathrm{Ag}_{3}$ are the biding, not biding and antibiding, respectively [17].

Fort he structure trimer neutral the bonding has been obtained with MP2/LANL2DZ, see Fig. 16, and are equal with reported in [39].

The optimized structure are pictored in the following figure, when the biding are in $\AA$.

$$
\text { a)IIa } C_{2 v},{ }^{2} A^{?},\left(0.18 \text { b)IIb } 0^{3.01} \mathrm{c}\right) \mathrm{IIc}
$$

Fig. 10. The structure of trimer clusters with HF/LANL1MB: a) neutral; b) anions; c) cations. Between parenthesis are reported the relative energy, $\triangle E$, (eV), and biding energy for atom $(\mathrm{eV})$

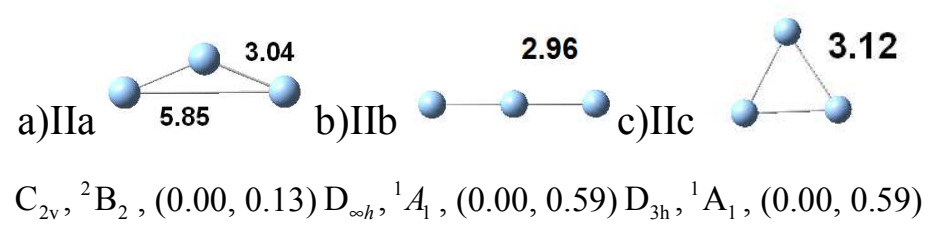

Fig. 11. The structure of trimer clusters with HF/LANL2MB: a) neutral; b) anions; c) cations. Between parenthesis are reported the relative energy, $\triangle E$, (eV), and biding energy for atom $(\mathrm{eV})$

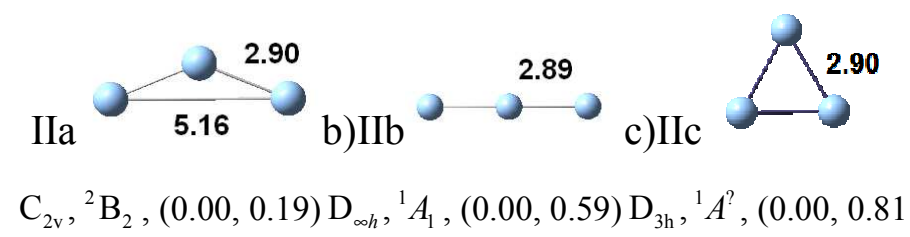

Fig. 12. The structure of trimer clusters with HF/LANL2DZ: a) neutral; b) anions; c) cations. Between parenthesis are reported the relative energy, $\triangle E$, (eV), and biding energy for atom $(\mathrm{eV})$

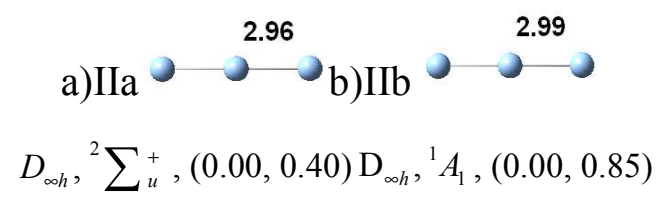




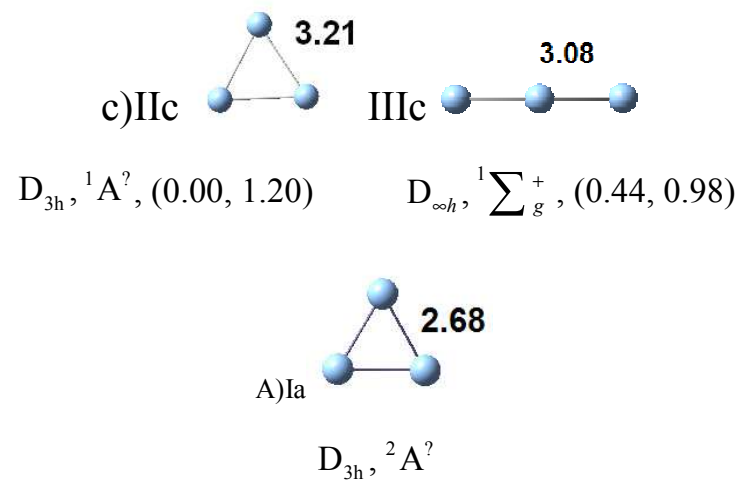

Fig. 13. The structure of trimer clusters with B3LYP/LANLIMB: a) neutral; b) anions; c) cations. Between parenthesis are reported the relative energy, $\triangle E$, $(\mathrm{eV})$, and biding energy for atom (eV). A) neutral in water.

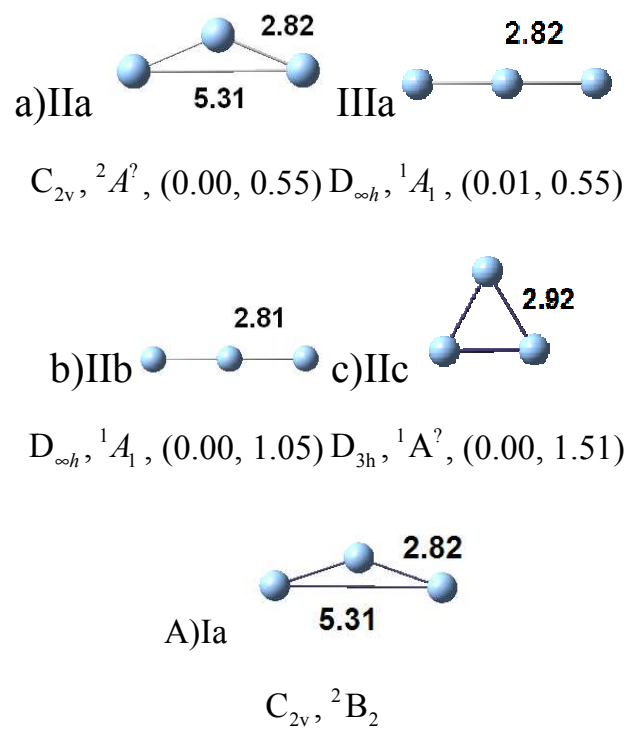

Fig. 14. The structure of trimer clusters with B3LYP/LANL2MB: a) neutral; b) anions; c) cations. Between parenthesis are reported the relative energy, $\triangle E$, $(\mathrm{eV})$, and biding energy for atom (eV). A) neutral in water

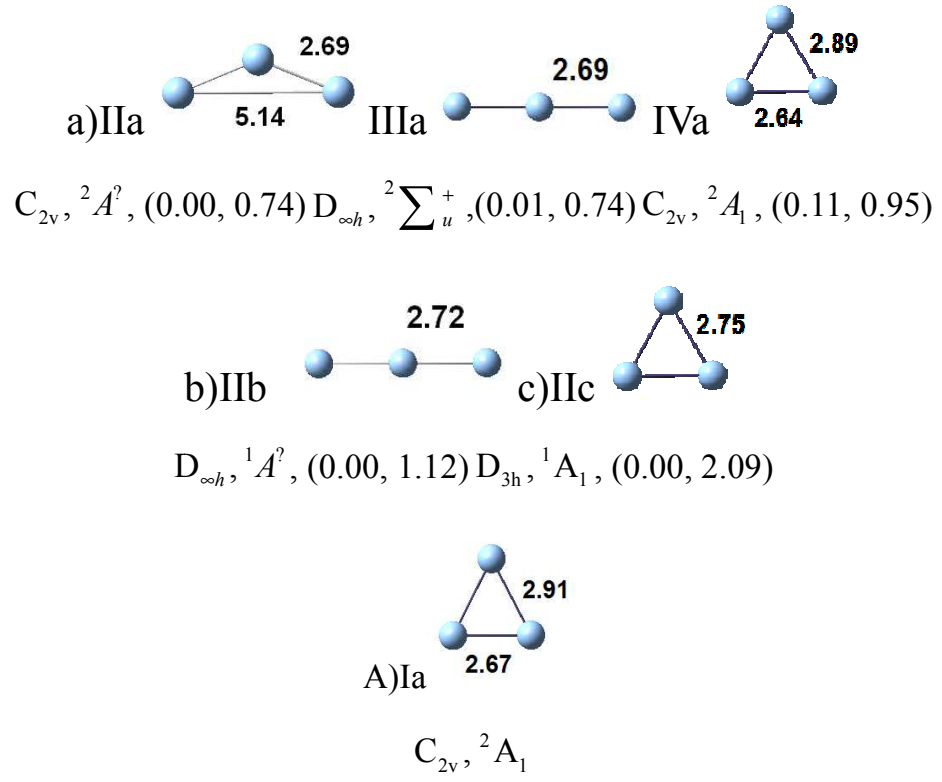

Fig. 15. The structure of trimer clusters with B3LYP/LANL2DZ: a) neutral; b) anions; c) cations. Between parenthesis are reported the relative energy, $\triangle E$, $(\mathrm{eV})$, and biding energy for atom (eV). A) neutral in water 


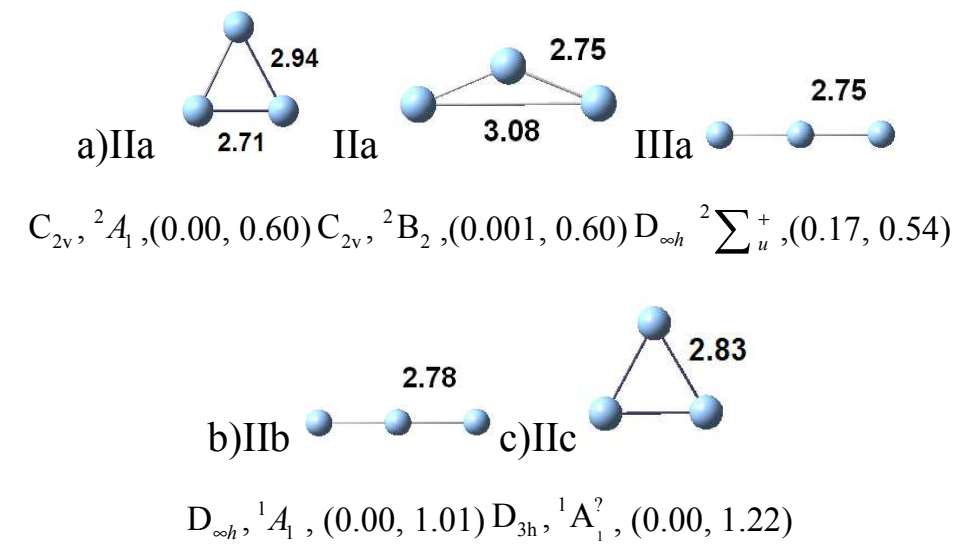

Fig. 16. The structure of trimer clusters with MP2/LANL2DZ: a) neutral; b) anions; c) cations. Between parenthesis are reported the relative energy, $\triangle E$, (eV), and biding energy for atom $(\mathrm{eV})$

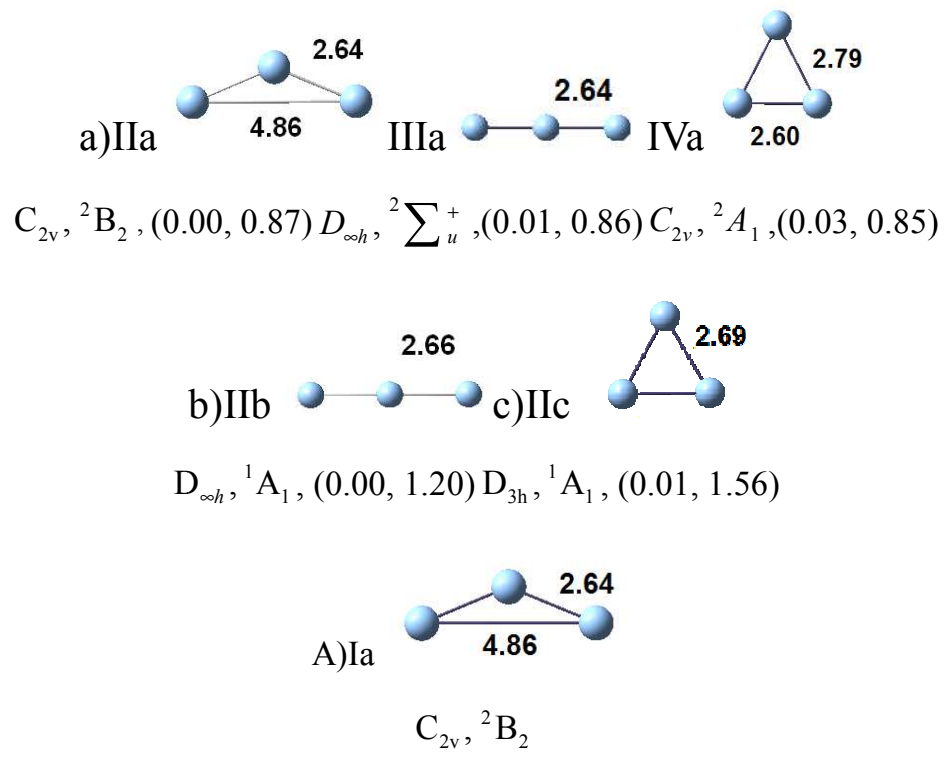

Fig. 17. The structure of trimer clusters with PBE/SDD: a) neutral; b) anions; c) cations. Between parenthesis are reported the relative energy, $\triangle E$, (eV), and biding energy for atom $(\mathrm{eV})$

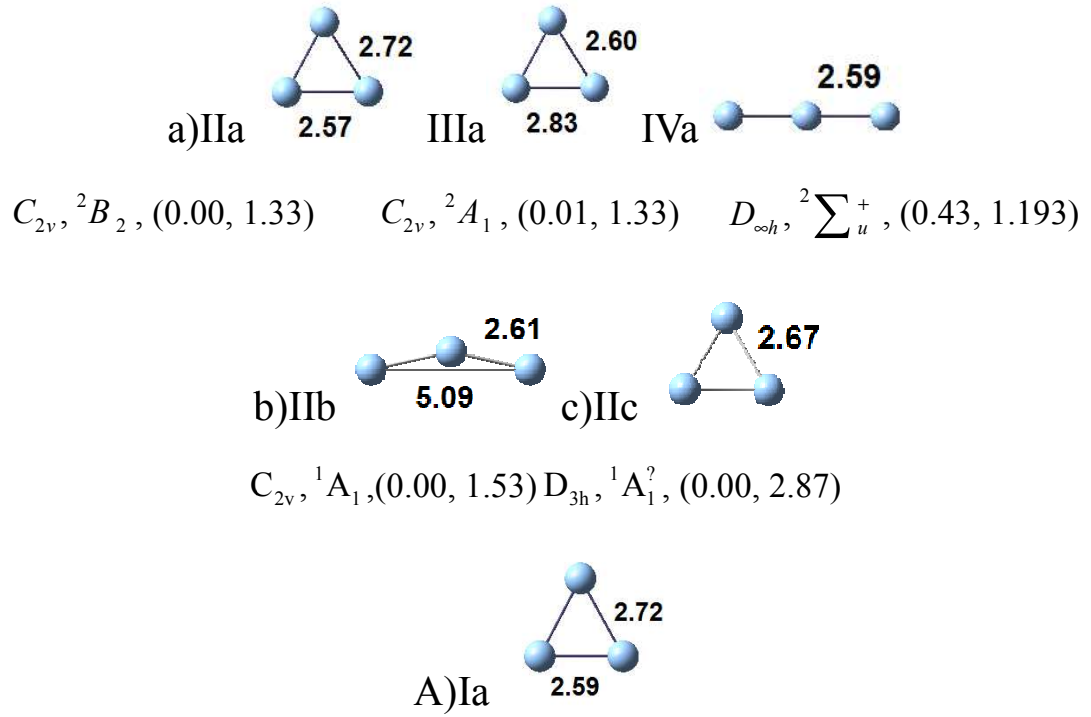

Fig. 18. The structure of trimer clusters with PBE/3-21G**: a) neutral; b) anions; c) cations. Between parenthesis are reported the relative energy, $\triangle E$, (eV), and biding energy for atom (eV). A) neutral in water 
The structure of obtuse triangle otimized with HF/LANL1MB are the angle $148.74^{\circ}$ and the distances 3.21 and $6.18 \AA$, see Fig. 10 (IIa).

Used the HF/LANL2DZ for the 3 atoms clusters exist also the contraction of the bonding for the relativistic effect, see Fig. 12 (IIa).

Analize the Fig. 17 (IIa) y 18 (IIa) I observed who the electronic correlation effects are competitivlly with the relativist effects for trimer structure has been the difference for the biding of 0.04 and $2.03 \AA$. Moreover, compared with B3LYP/LANL2DZ where are obtained 2.69 SDD and PBE to influence of geometrical property of $\mathrm{Ag}_{3}$.

Except when are employed PBE/3-21G** the anion cluster are for all levels of theory the linear geometry.

For the anion cluster with DFT/PBE/3-21G** has been obtained the triangular structure lees stable by $1.3 \mathrm{eV}$ who linear structure [51].

To compare the DFT/B3LYP and HF, and employed LANL2DZ, have been obtained the difference of $0.21 \AA$, see Fig. 15 (IIIa) y Fig. 12 (IIIa).

In the case of $\mathrm{Ag}_{3}$ the electronic correlation efects alone or complementary with relativistic effects (PBE/SDD) are strived. For anions structures the more stable are the lineal structure, for neutral structure the obtuse-angled triangle and for the cation the equilateral triangle.

\subsection{Tetramer and Pentamer Neutral, Anions and Cations}

The $\mathrm{Ag}_{4}$ structure are HOMO doubly ocuped in the singlete. Compared the rhombic structure of neutral cluster in la Fig. 21 (IIIa) and the cation cluster, see Fig. 21 (IVc), optimized with HF/LANL2DZ, I observ who the distance are minor for neutral cluster who cation cluster $(2.77$ y $2.83 \AA$ ).

Beteen two central atoms, possibly on account of in part of the $p$ atomic orbitals to bind weakly in HOMO with another atoms allowances above the greater diagonal. For such motive in the neutral cluster doubly occupied in HOMO the distance beteen two atoms are less who in the cation.

The same to present for the silver when are performed with PBE/SDD, see Fig. 26 (IIIa y IIIc) and the optimized cluster with MP2, see Fig. 25 (IIIa y IIIc).

Fort he romboidal structure, the experimental distance are reported in [39] is $2.79 \AA$ comparison with $2.81 \AA$ obtained in the present work, see Fig. 24 (IIIa). The form $\mathrm{T}$ is very stable, successively for romboidal and lineal structure.

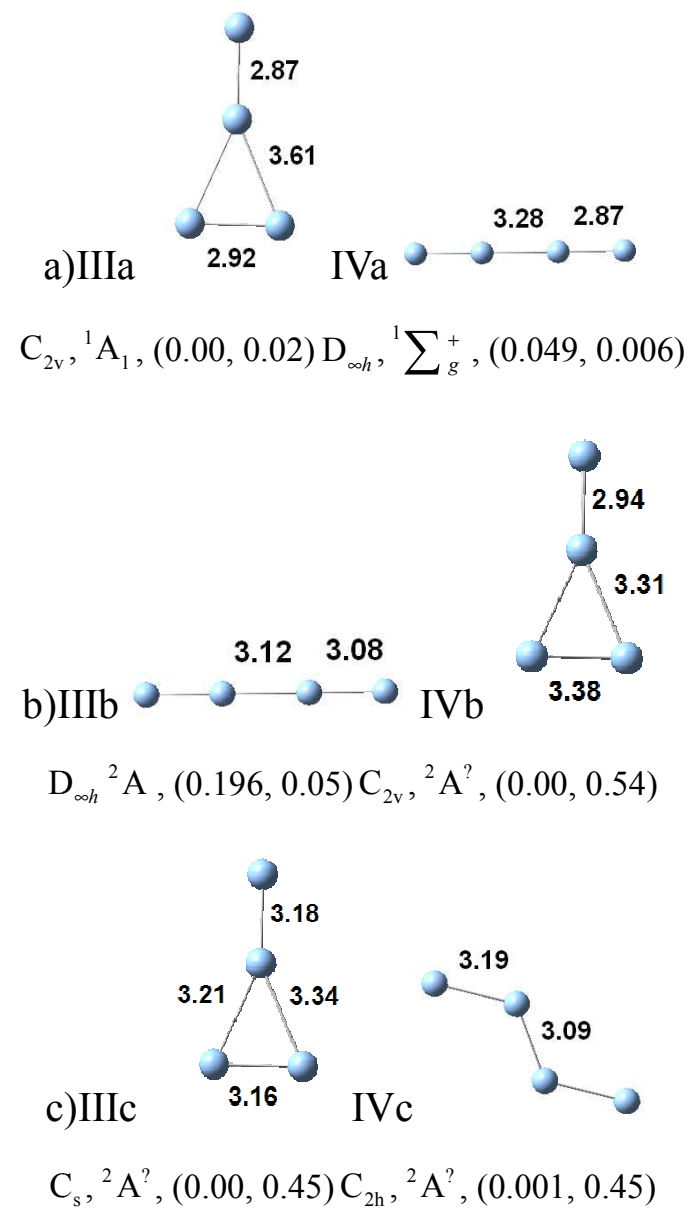

Fig. 19. The structure of $\mathrm{Ag}_{4}$ clusters with HF/LANL1MB: a) neutral; b) anions; c) cations. Between parenthesis are reported the relative energy, $\triangle E$, (eV), and biding energy for atom $(\mathrm{eV})$ 


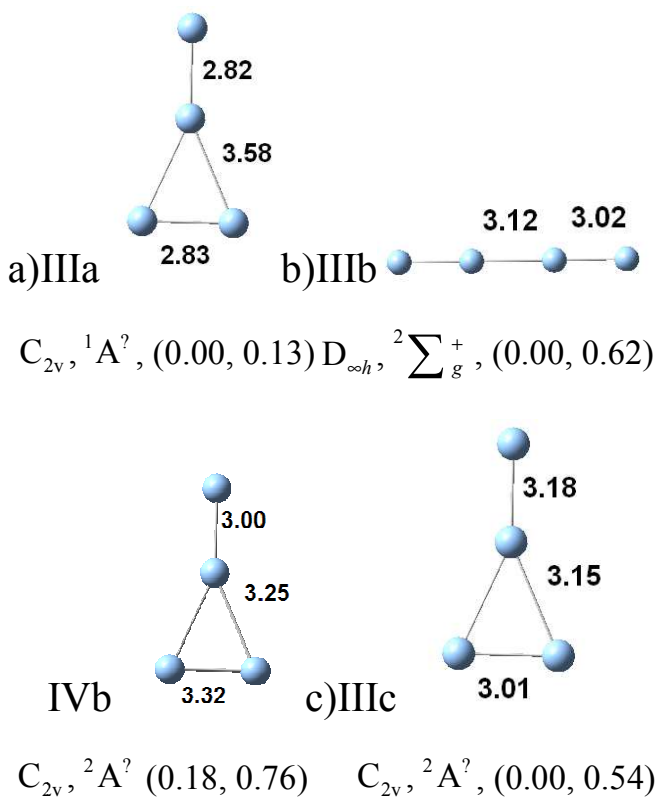

Fig. 20. The structure of $\mathrm{Ag}_{4}$ clusters with $H F / L A N L 2 M B:$ a) neutral; b) anions; c) cations. Between parenthesis are reported the relative energy, $\triangle E$, (eV), and biding energy for atom $(\mathrm{eV})$

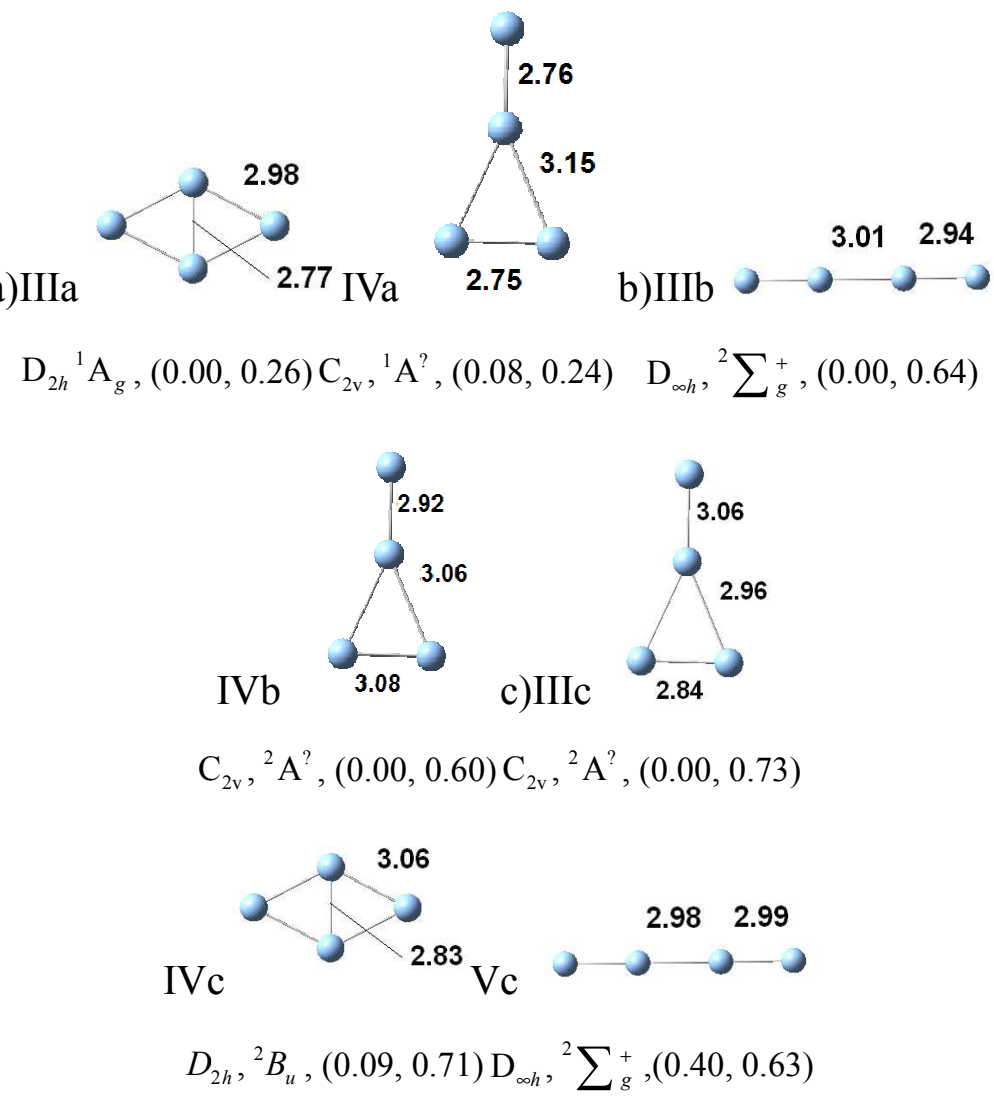

Fig. 21. The structure of $A g_{4}$ clusters with $H F / L A N L 2 D Z:$ a) neutral; b) anions; c) cations. Between parenthesis are reported the relative energy, $\triangle E$, (eV), and biding energy for atom $(\mathrm{eV})$ 


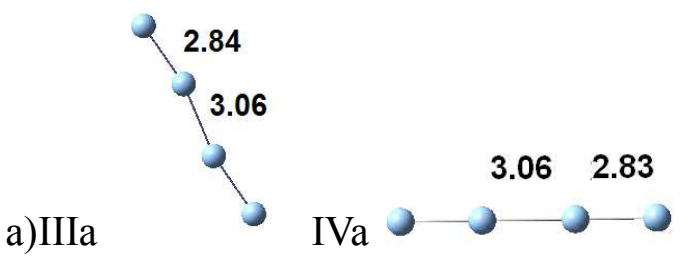

$$
\mathrm{C}_{2 \mathrm{~h}}, \mathrm{~A}^{1},(0.000,0.51) \mathrm{D}_{\infty \mathrm{h}},{ }^{1} \sum_{g}^{+},(0.0002,0.51)
$$

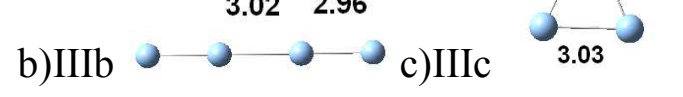

$$
\mathrm{D}_{\infty \mathrm{h}},{ }^{2} \sum_{g}^{+},(0.00,0.83) \mathrm{C}_{2 \mathrm{v}},{ }^{2} \mathrm{~A}^{?},(0.00,1.55)
$$

Fig. 22. The structure of $\mathrm{Ag}_{4}$ clusters with B3LYP/LANL1MB: a) neutral; b) anions; c) cations. Between parenthesis are reported the relative energy, $\triangle E$, (eV), and biding energy for atom $(\mathrm{eV})$

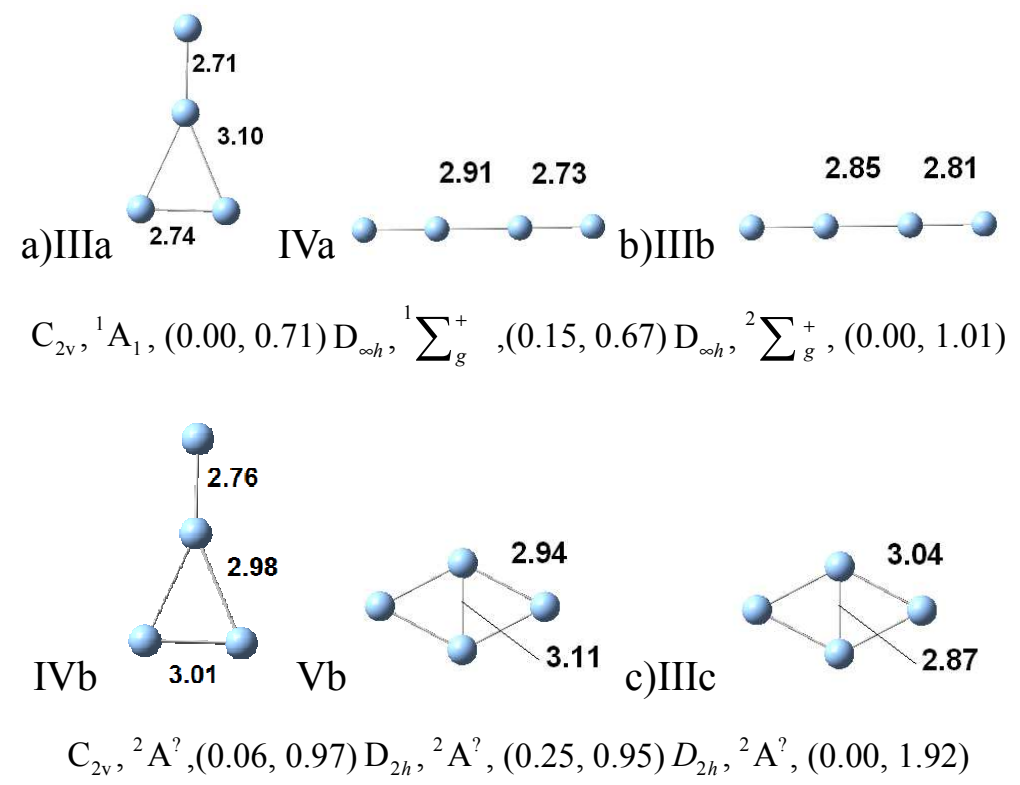

Fig. 23. The structure of $\mathrm{Ag}_{4}$ clusters with B3LYP/LANL2MB: a) neutral; b) anions; c) cations. Between parenthesis are reported the relative energy, $\triangle E$, (eV), and biding energy for atom $(\mathrm{eV})$

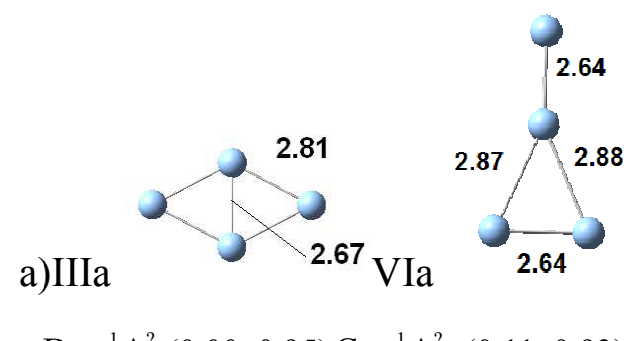

$$
\mathrm{D}_{2 h},{ }^{1} \mathrm{~A}^{?},(0.00,0.95) \mathrm{C}_{2 \mathrm{~s}},{ }^{1} \mathrm{~A}^{?},(0.11,0.93)
$$




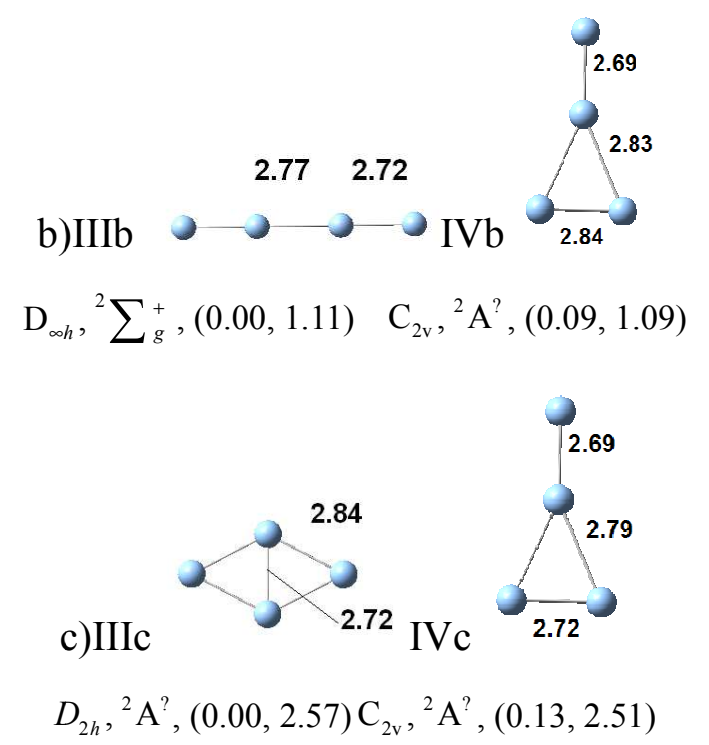

Fig. 24. The structure of $\mathrm{Ag}_{4}$ clusters with B3LYP/LANL2DZ: a) neutral; b) anions; c) cations. Between parenthesis are reported the relative energy, $\triangle E$, (eV), and biding energy for atom $(\mathrm{eV})$

a)IIIa
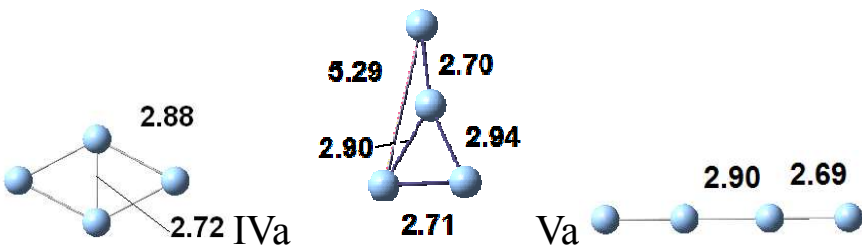

$\mathrm{D}_{2 h},{ }^{1} \mathrm{~A}_{g},(0.00,0.87) \mathrm{C}_{\mathrm{s}},{ }^{1} \mathrm{~A}^{?},(0.28,0.80) \mathrm{D}_{\infty h},{ }^{1} \sum_{g}^{+},(0.78,0.68)$
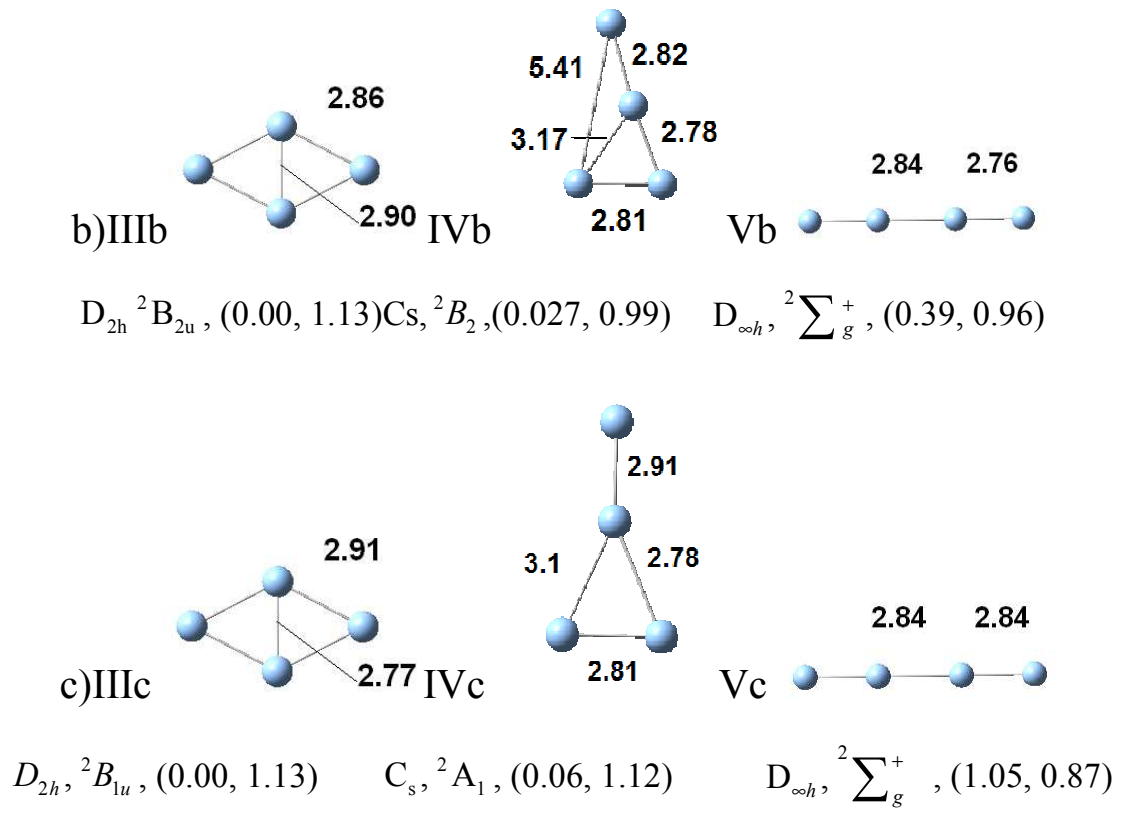

Fig. 25. The structure of $\mathrm{Ag}_{4}$ clusters with MP2/LANL2DZ: a) neutral; b) anions; c) cations. Between parenthesis are reported the relative energy, $\triangle E$, (eV), and biding energy for atom (eV) 


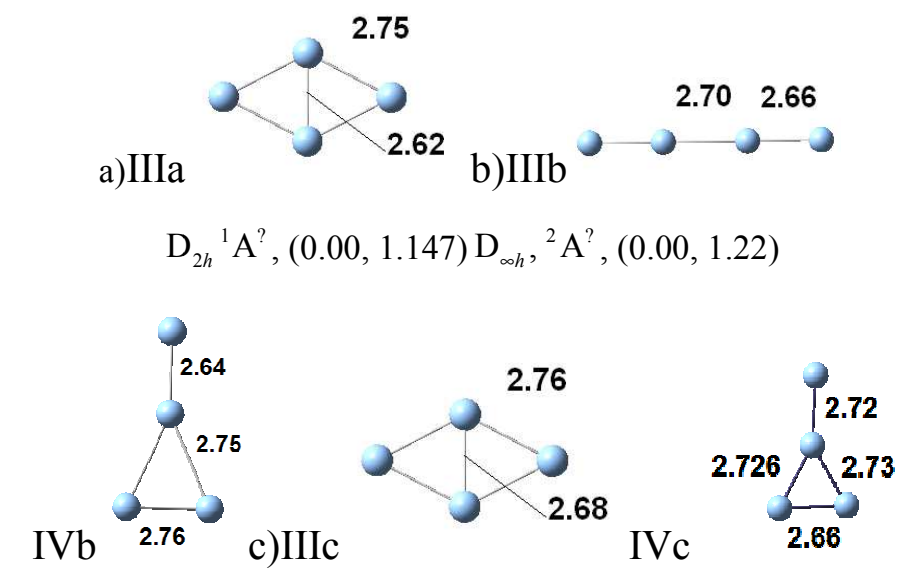

$C_{2 v},{ }^{2} \mathrm{~A}^{?},(0.021,1.21) D_{2 h},{ }^{2} \mathrm{~A}^{?},(0.00,1.49) \mathrm{C}_{\mathrm{s}},{ }^{2} \mathrm{~A}^{?},(0.24,1.43)$

Fig. 26. The structure of $\mathrm{Ag}_{4}$ clusters with PBE/SDD: a) neutral; b) anions; c) cations. Between parenthesis are reported the relative energy, $\triangle E$, (eV), and biding energy for atom $(\mathrm{eV})$

a) IIIa

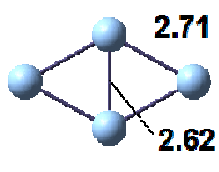

b)IIIb

$$
\mathrm{D}_{2 h},{ }^{1} \mathrm{~A}^{?}(0.00,1.69) D_{2 h},{ }^{2} \mathrm{~A}^{?}(0.00,1.84) D_{2 h},{ }^{2} \mathrm{~A}^{?},(0.00,3.89)
$$

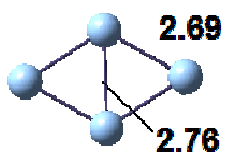

2.73

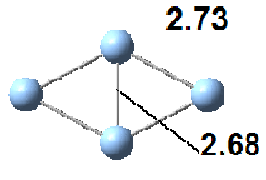

Fig. 27. The structure of $\mathrm{Ag}_{4}$ clusters with PBE/3-21G**: a) neutral; b) anions; c) cations. Between parenthesis are reported the relative energy, $\triangle E$, (eV), and biding energy for atom $(\mathrm{eV})$

In [44] has been reportade the distance for $\mathrm{Ag}_{4}^{-}$anions cluster obtained with SCF 1e-RECP-CVC. Romboedral the $2.789 \AA$ and $2.838 \AA$ with difference of $0.02 \AA$ of the distance obtained optimized with $\mathrm{PBE} / \mathrm{SDD}$, but less who $2.69 \AA$ obtained with DFT and PBE AND 3-21G**.

For $\mathrm{Ag}_{4}$ neutral cluster are performed with HF/LANL2DZ and B3LYP/LANL2DZ

Comparison the distance beteen atoms in the neutral cluster with rombic structure optimized rebound who contraction for electronic correlation is $0.17 \AA$ and $0.10 \AA$, see Fig. 21 y 24 (IIIa y IIIa).

For cations cluster in Fig. 21 and 24 (IIIb, IVb, IIIb y IIIc) the the contraction are $0.25 \AA$, greater who in the neutral clusters. For catión in wáter the sistance are les that in gas phase, but neutral cluster are more distance that in gas phase.

Beteen the neutral structure optimized with 5 atoms with DFT/B3LYP/LANL2DZ, the trpezium es better stable who piramidal with squere base so how are moderate in [18] how experimental date.
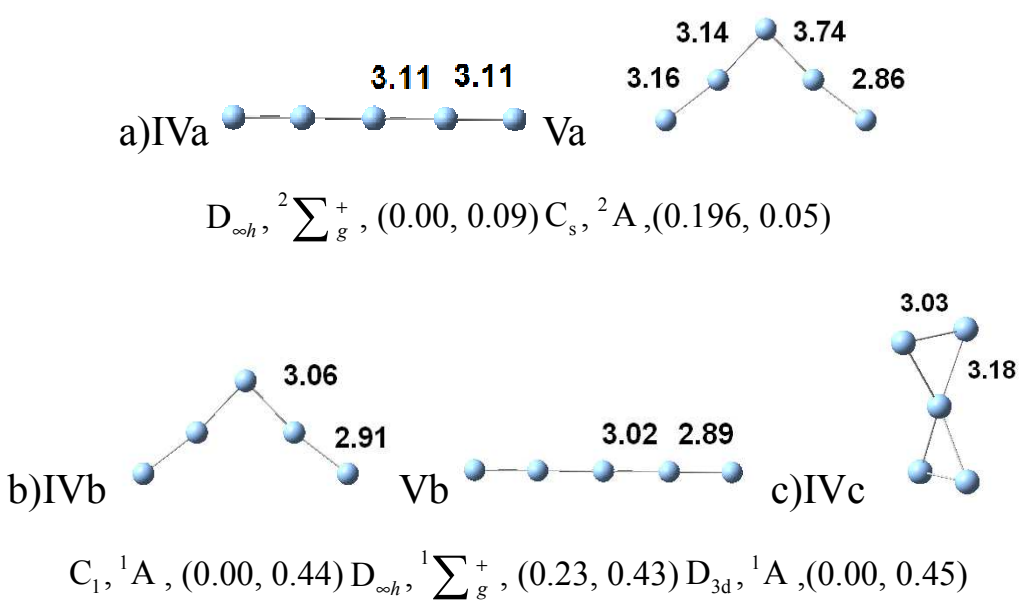

Fig. 28. The structure of $A g_{5}$ clusters with HF/LANL1MB: a) neutral; b) anions; c) cations. Between parenthesis are reported the relative energy, $\triangle E$, (eV), and biding energy for atom $(\mathrm{eV})$ 


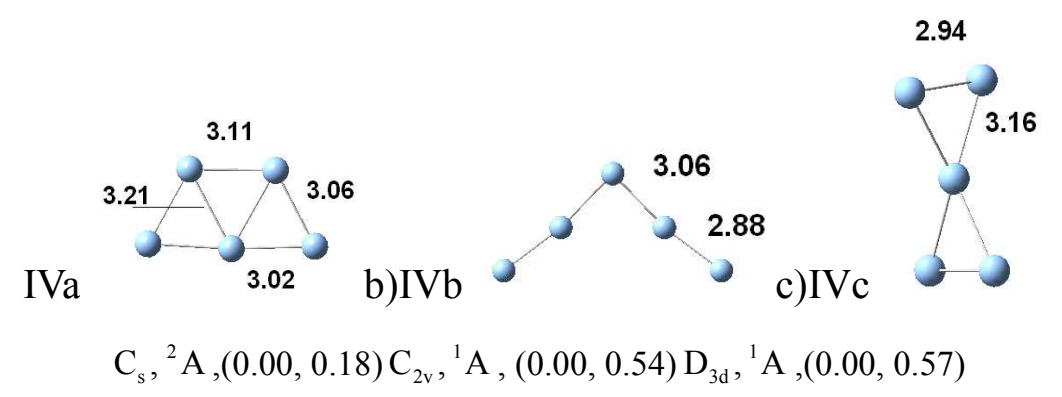

Fig. 29. The structure of $A g_{5}$ clusters with HF/LANL2MB: a) neutral; b) anions; c) cations. Between parenthesis are reported the relative energy, $\triangle E$, (eV), and biding energy for atom (eV)

a)IVa

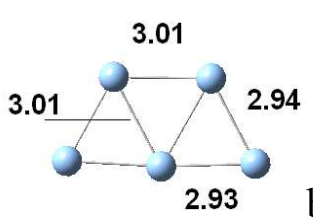

b) $\mathrm{IVb}$

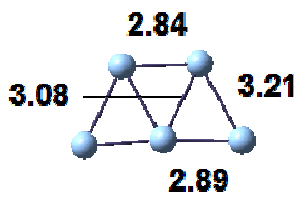

$\mathrm{C}_{2 \mathrm{v}},{ }^{2} \mathrm{~A},(0.00,0.36) \mathrm{C}_{2 \mathrm{v}},{ }^{1} \mathrm{~A}^{?},(0.00,0.55)$

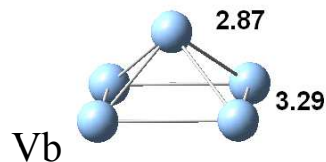

c)IVc

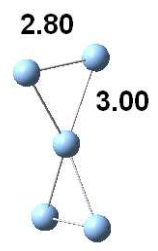

$\mathrm{C}_{4 v},{ }^{1} \mathrm{~A},(0.49,0.45) \quad \mathrm{D}_{3 d},{ }^{1} \mathrm{~A},(0.00,0.77)$

Fig. 30. The structure of $A g_{5}$ clusters with HF/LANL2DZ: a) neutral; b) anions; c) cations. Between parenthesis are reported the relative energy, $\Delta E$, (eV), and biding energy for atom $(\mathrm{eV})$

a)IVa

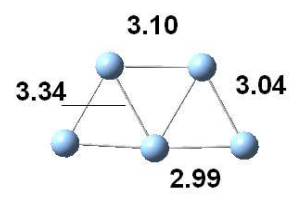

b) $\mathrm{IVb}$

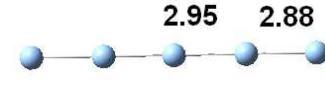

c)IVc
2.93

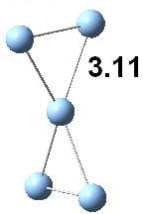

$$
\mathrm{C}_{\mathrm{s}},{ }^{2} \mathrm{~A}^{?},(0.00,0.47) \mathrm{D}_{\infty h}, \sum_{g}^{+},(0.00,0.87) \mathrm{D}_{3 \mathrm{~d}},{ }^{1} \mathrm{~A},(0.00,2.23)
$$

Fig. 31. The structure of $\mathrm{Ag}_{5}$ clusters with B3LYP/LANL1MB: a) neutral; b) anions; c) cations. Between parenthesis are reported the relative energy, $\triangle E$, (eV), and biding energy for atom $(\mathrm{eV})$

a)IVa

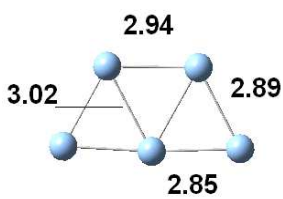

b) VIb

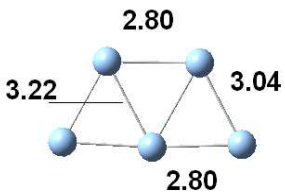

c)IVc

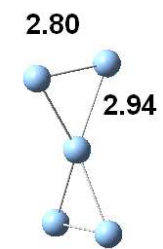

$$
\mathrm{C}_{2 v},{ }^{2} \mathrm{~A}^{?},(0.00,0.80) \mathrm{C}_{2 \mathrm{v}},{ }^{1} \mathrm{~A}^{?},(0.00,1.08) \mathrm{D}_{3 \mathrm{~d}},{ }^{1} \mathrm{~A},(0.00,2.85)
$$

Fig. 32. The structure of $\mathrm{Ag}_{5}$ clusters with B3LYP/LANL2MB: a) neutral; b) anions; c) cations. Between parenthesis are reported the relative energy, $\triangle E$, (eV), and biding energy for atom $(\mathrm{eV})$ 


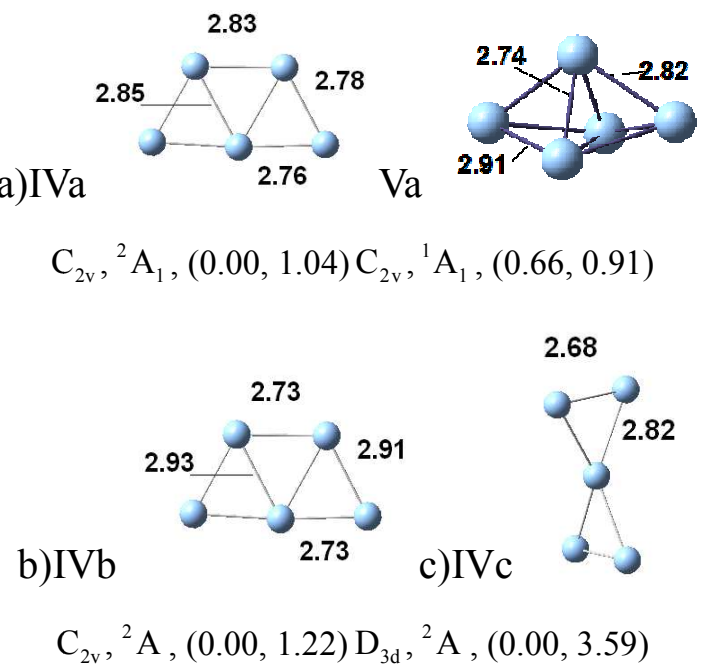

Fig. 33. The structure of $A g_{5}$ clusters with B3LYP/LANL2DZ: a) neutral; b) anions; c) cations. Between parenthesis are reported the relative energy, $\triangle E$, (eV), and biding energy for atom (eV)

b) $\mathrm{IVb}$

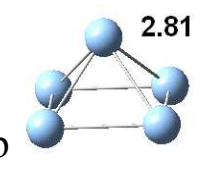

2.99

$\mathrm{C}_{4 v},{ }^{1} \mathrm{~A},(0.00,1.16) \mathrm{D}_{3 \mathrm{~h}},{ }^{1} \mathrm{~A},(0.00,1.23)$
2.97

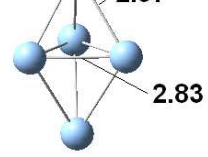

c)IVc

2.83

Fig. 34. The structure of $A g_{5}$ clusters with MP2/LANL2DZ: a) neutral; b) anions; c) cations. Between parenthesis are reported the relative energy, $\triangle E$, (eV), and biding energy for atom (eV)

I oberve the influyence of the relativistic effects for $\mathrm{Ag}_{5}^{+}$ employed HF/LANL1MB, HF/LANL2MB and HF/LANL2DZ with the contraction of 0.09 and $0.06 \AA$ in distance, see Fig. 28 (IVc), 29 (IVc) and 30 (IVc). With B3LYP the difference beteen distance in $\mathrm{C}_{2 v},{ }^{1} \mathrm{~A}_{1}$ is the 0.16 $\AA$ with $\mathrm{Ag}_{5}$ optimized with HF/LANL2DZ,see Fig. 21 (Va) and Fig. 33 (IVa).

On change comparatively the variation of distance beteen the structure optimized trapezoidal with B3LYP/LANL1MB and B3LYP/LANL2DZ the difference are $0.26 \AA$ who to oppose who relativist effect are greater who the electronic correlation, the plan estructure has been more stable when the bipiramydal structure with triangle base, so report in experimental data [18].

This debit of hybridization beteen $4 d$ y $5 s$ that to favor the planar structure. The hibridization are interesinteresting for the relativistic effects in $\mathrm{Au}, \mathrm{Cu}$ and silver, in this case particular [59].

Fort he silver plata $A g_{7}$ rebound to be who the planar structure is stable with diminution in distance, so how $A u_{7}$ [67].

\section{Biding Energy for Atom}

Is important to study the biding energy for atom because to refer at stability of clusters. Are graphical the value of the biding energy of the neutral cluster, anions and cations Fig. 35-43 calculated with $\frac{E_{b}}{n}=\left(n E_{1}-E_{n}\right) / n$ where $E_{1}$ and $E_{n}$ are the total energy for the neutral species optimizated for un atom and $\mathrm{n}$ atoms;

$$
\frac{E^{ \pm}}{n}=\left[(n-1) E_{1}+E_{1}^{ \pm}-E_{n}^{ \pm}\right] / n
$$

where $E_{1}^{ \pm}$and $E_{n}^{ \pm}$are the total energy for the positive and negative for un atom and $\mathrm{n}$ atoms.

In Fig. 35 are presented the reults obtained for the neutral clusters of $\operatorname{Ag}_{n}(n=1-5)$. Tendency in the values of biding energy of the cluster augment with the number of atoms employed the HF/LANL2DZ level. Th estructure $\mathrm{T}$ for $\mathrm{Ag}_{4}$ optimized with LANL2MB and LANL1MB is less stable who the triangular, rombic and lineal structure

In Jahn-Teller for the neutral clusters $\mathrm{Ag}_{3}$ optimized with HF/LANLEDZ resulte who el isomer more stable are the optuse triangle with the biding energy with $0.193 \mathrm{eV}$, successive for the lineal structure with biding energy of 0.191 $\mathrm{eV}$ and, for the last is the $C_{2 v}{ }^{2} A_{1}$ structure with $0.161 \mathrm{eV}$, see Fig. 32 (IIa, IIIa y IVa), when this are not the experimental reported where the ${ }^{2} B_{2}$ is better stable who ${ }^{2} A_{1}$ $[48,50]$.

In the Fig. 19 has been optimized the $D_{\infty h,}, \sum_{g}^{+}$lineal with $\mathrm{HF} / \mathrm{LANL} 1 \mathrm{MB}$, for $\mathrm{Ag}_{4}$ and are the value $0.013 \mathrm{~V}$ who 
the T form with $C_{2 v},{ }^{1} A_{1}$ simmetry Fig. 19 (IIIa).

For $\mathrm{Ag}_{4}$ optimized with HF/LANL2DZ the structure more stableis rombic with the little diference $0.12 \mathrm{eV}$, for biding energy, with the T form with $C_{2 v},{ }^{1} A_{1}$ simmetry, see Fig. 21

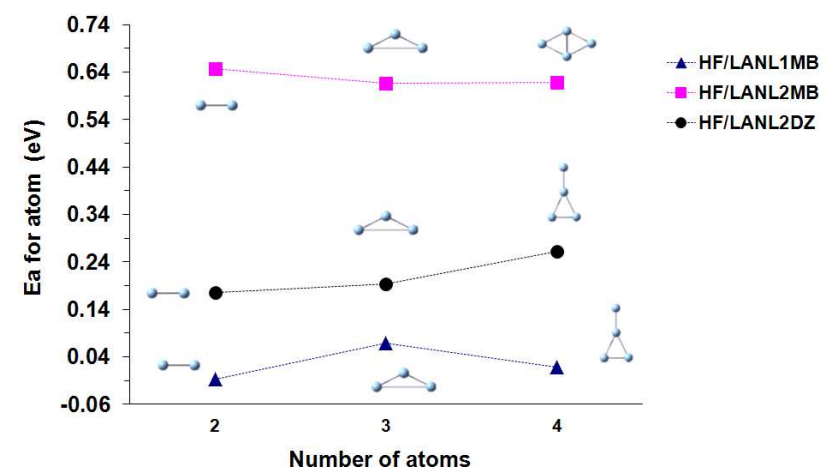

Fig. 35. Biding energy for atom for neutral clusters employed HF. VS. Number of atom for clusters. The mast stable structure. [80]

For anions clusters, see Fig.36, for $\mathrm{Ag}_{3}$ and $\mathrm{Ag}_{4}$, the form more stable are lineal. For Ag4 anion optimized with LANL1MB the lineal form is more stable who $\mathrm{T}$ form with 0.08 eV only see Fig. 19.

The distribution of charge after to remove 1 electron for $\mathrm{Ag}_{4}^{+}$to favor the $\mathrm{T}$ form how more stable with biding energy $0.73 \mathrm{eV}$, the act of following for rombic and lineal structure with 0.71 and $0.63 \mathrm{eV}$.

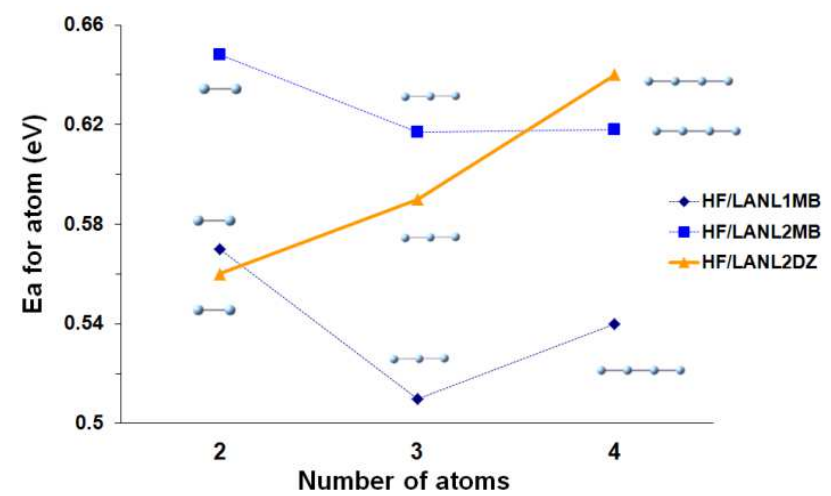

Fig. 36. Biding energy for atom for neutral clusters employed HF. Vs. Number of atom for clusters. The mast stable structure. [80]

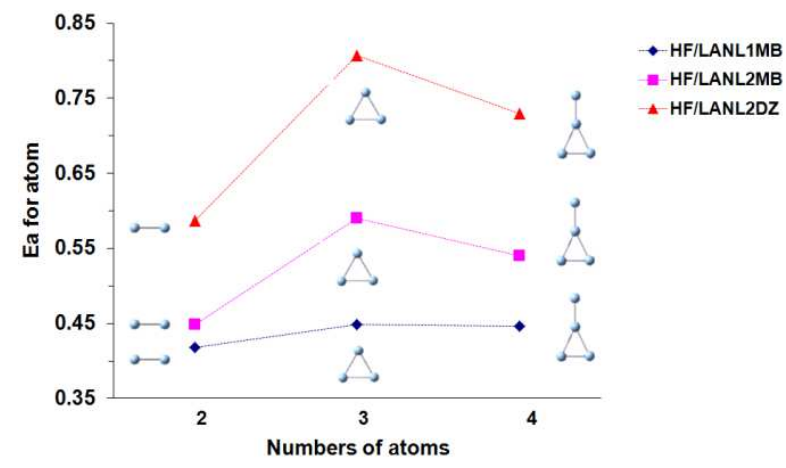

Fig. 37. Biding energy for atom for neutral clusters employed HF. Vs. Number of atom for clusters. The mast stable structure.[80]
In the Fig. 38 are graphicate the value of biding energy for the neutral of silver with 2 and 4 atoms. When are optimized the cluster with B3LYP/LANL1MB han been optained lees value for $\mathrm{Ag}_{\mathrm{n}}(\mathrm{n}=2-4) 0.446 \mathrm{eV}, 0.403 \mathrm{eV}$ and $0.511 \mathrm{eV}$, see Fig. 38.

The value of biding energy for dimer clusters obtained with PBE/SDD and B3LYP/LANL2DZ of $0.876 \mathrm{eV}$ and $0.776 \mathrm{eV}$ near of the data experimental [60].

The binding energy obtained for the isomer ${ }^{2} B_{2},{ }^{2} \sum_{u}^{+}$ and ${ }^{2} A_{1}$ obtained $\mathrm{Ag}_{3}$ with B3LYP/LANL2DZ has been $0.740 \mathrm{eV}, 0.705$ y $0.738 \mathrm{eV}$.

In this case has been different to the experimentals results where the diference beteen ${ }^{2} B_{2}$ and ${ }^{2} A_{1}$ are the $0.022 \mathrm{eV}$ [61] and, beteen ${ }^{2} B_{2}$ y ${ }^{2} \sum_{u}^{+}$are $0.15 \mathrm{eV}$ in [38] or the value 0.85 $\mathrm{eV}$ reported in [48].

When has been optimized with MP2/LANL2DZ the difference beteen ${ }^{2} A_{1}$ and ${ }^{2} B_{2}$ is the $0.001 \mathrm{eV}$ only the biding energy are the same $0.6 \mathrm{eV}$. For PBE/3-21G** has been see greater values, see Fig. 38, and the biding energy concured with the report in the literatura [60].

For $\mathrm{Ag}_{4}^{-}$optimized with B3LYP/LANL2MB the $D_{\infty h},{ }^{2} \sum_{g}^{+}$are biding energy for atom of $1.01 \mathrm{eV}$ compared with de T form who are $0.97 \mathrm{eV}$ and $D_{2 h},{ }^{2} B_{2 u}$ with $0.95 \mathrm{eV}$ (see Fig. 23).

Employed PBE/SDD level of theory for optained $\mathrm{Ag}_{4}^{-}$the difference between lineal structure end $\mathrm{T}$ form are $0.01 \mathrm{eV}$, implicated who energy for separation the two structure is almost equal. On the contrary, employed MP2/LANL2DZ level of theorie in the Fig. 25 see who lineal structure $\mathrm{Ag}_{4}^{-}$ are the biding energy minor $(0.96 \mathrm{eV})$ who structure $D_{2 h},{ }^{2} B_{2}$ with $0.99 \mathrm{Ev}$ and rombic structure $D_{2 h},{ }^{2} B_{2 u}$ with $1.13 \mathrm{eV}$.

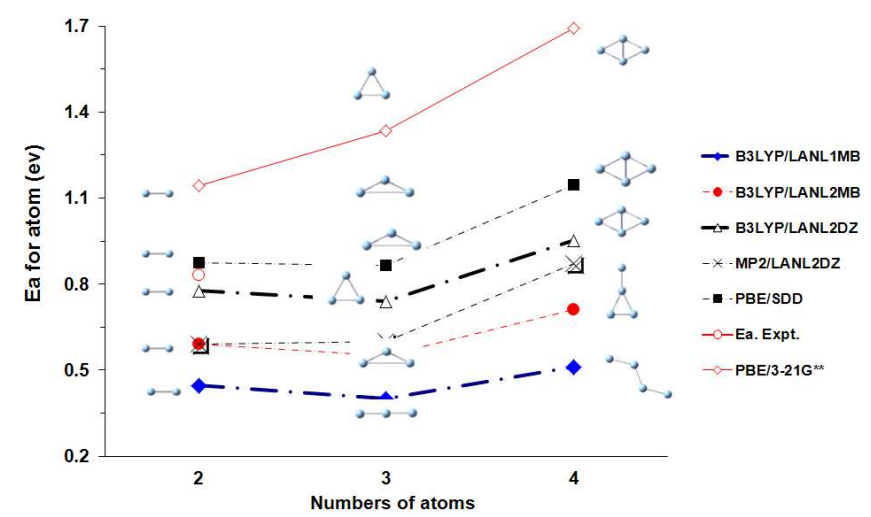

Fig. 38. Biding energy for atom for neutral clusters employed DFT. Vs. Number of atom for clusters. Ea experimental [36].The mast stable structure.[80] 


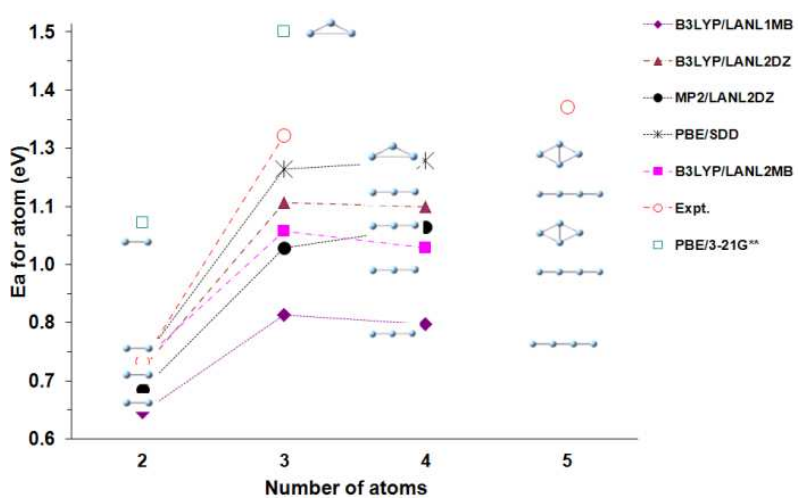

Fig. 39. Biding energy for atom for neutral clusters employed DFT. VS. Number of atom for clusters. E Experimental [36].The mast stable structure.[80]

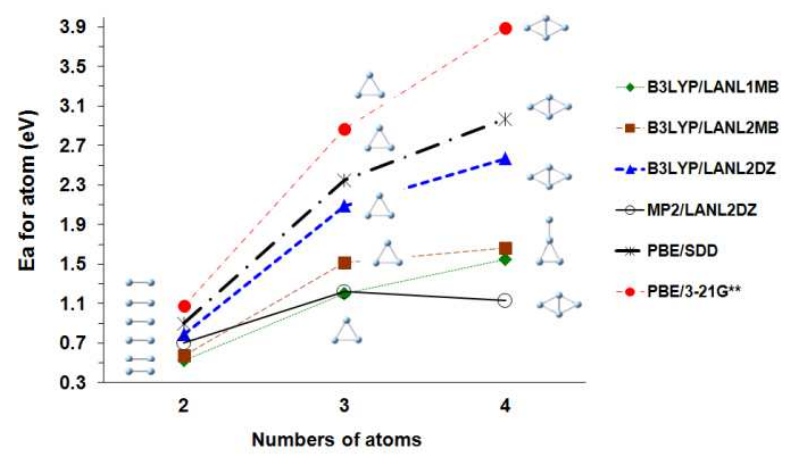

Fig. 40. Biding energy for atom for neutral clusters employed DFT. Vs. Number of atom for clusters. The mast stable structure. [80]

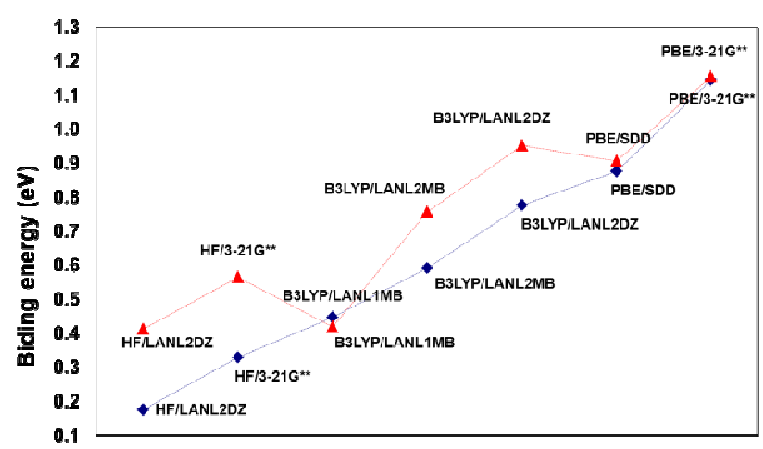

Fig. 41. Biding energy for atom for neutral dimer clusters in water in red in water and blue in gas phase. Vs. Number of atom for clusters. The mast stable structure.

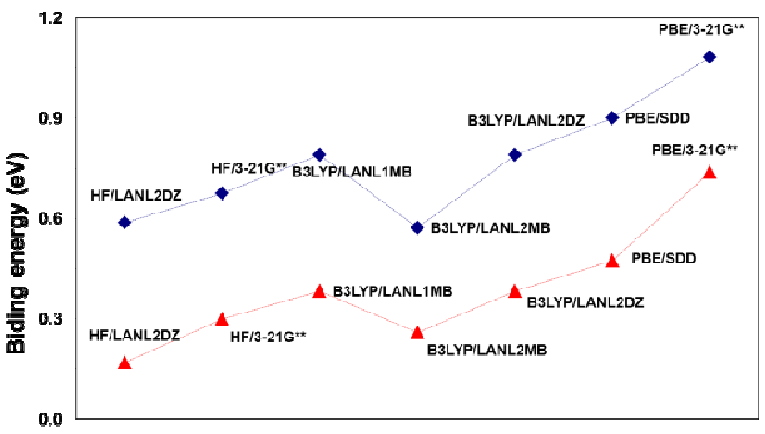

Fig. 42. Biding energy for atom for dimer cations clusters in water in red in water and blue in gas phase. Vs. Number of atom for clusters. The mast stable structure.

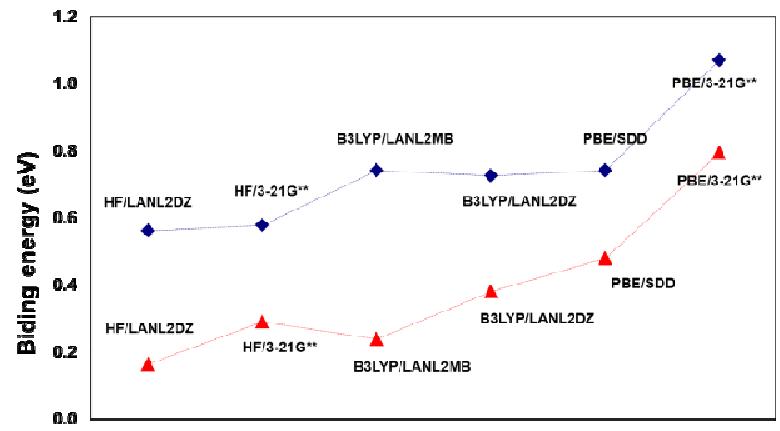

Fig. 43. Biding energy for atom for dimer anions clusters in water in red in water and blue in gas phase. Vs. Number of atom for clusters. The mast stable structure.

\section{Ionization Potential and Electronic Affinity}

\subsection{Adiabatic Electronic Affinity and Vertical}

In this section are show the values obtained for electronic affinitie and ionization potential for compared with the theoric result and experimental date and see which of the effects relativistic or electronic correlation interfer in this proprieties.

The calculus for the electronic affinities has been calculated with $A=E_{n}-E_{n}^{-}$, where $E_{n}$ is the total energy for the neutral species optimized and $E_{n}^{-}$is the total energy for the anion species after optimized.

How to observe in the Fig. 44 and 45 the values for electronic affinity are distant for the experimental data and are not the same tendency for the clusters optimized with HF and LANL1MB, LANL2MB and LANL2DZ bases.

This a shop sign who HF are not describet fitly the adiabatic electronic affinity for the silver clusters alredy who solely consider the relativistic effects and giving who understimade the difference of energy of the $A g_{n}$ and $A g_{n}^{-}$.

The difference for the silver clusters $\mathrm{Ag}_{3}$ are $1.5 \mathrm{eV}$ for $\mathrm{Ag}_{2}$ are $0.43 \mathrm{eV}$ and $\mathrm{Ag}_{4} 0.32 \mathrm{eV}$, see Fig. 46 .

Compared Fig. 44 and 45 has been observed who the results obtained for vertical electronic affinity concured with the adiabatic electronic affinitie motive for which is advisable employed vertical electronic affinity.

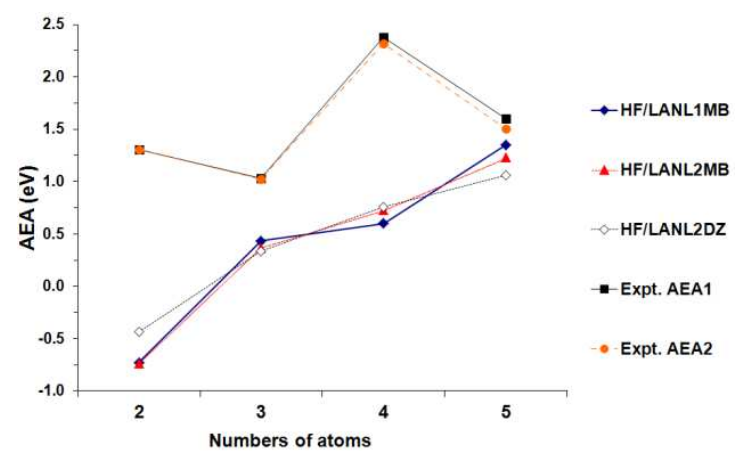

Fig. 44. Adiabatic electronic afinity for silver cluster employed. Vs. Number of atoms in the cluster. AEA1 experimental [61-63]. AEA2 experimental [37]. [80] 


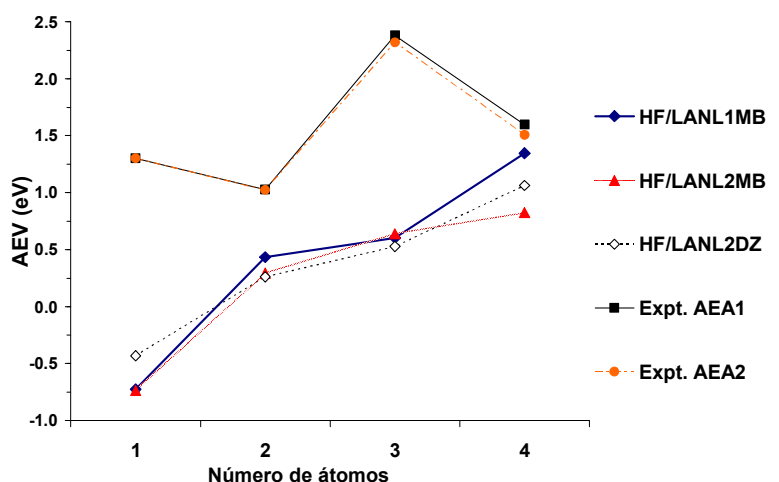

Fig. 45. Adiabatic electronic afinity for silver cluster employed HF. Vs. Number of atoms in the cluster. AEA1 experimental [61- 63]. AEA2 experimental [37], [80]

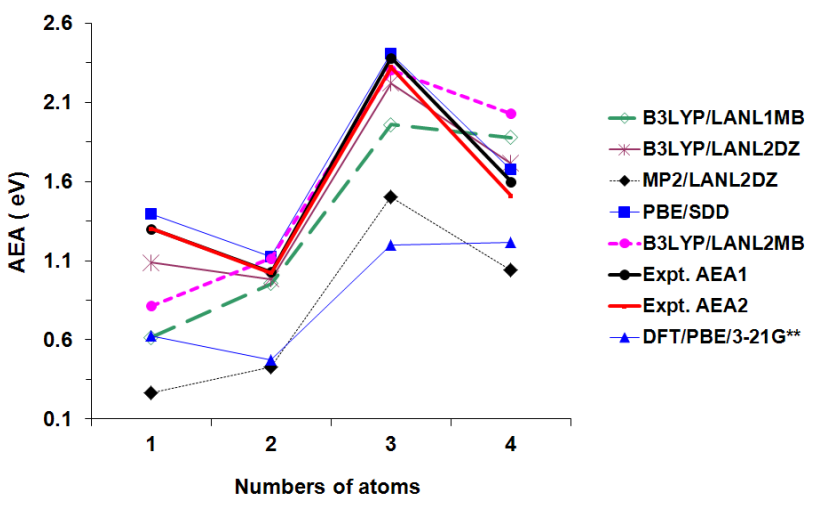

Fig. 46. Adiabatic electronic afinity for silver cluster employed DFT. VS. Number of atoms in the cluster. AEA1 experimental [61, 63]. AEA2 experimental [37], [80]

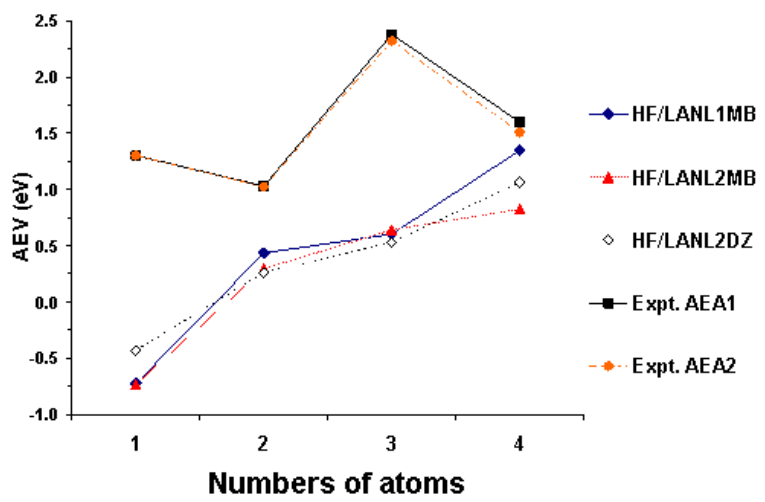

Fig. 47. Adiabatic electronic afinity for silver cluster employed DFT. VS. Number of atoms in the cluster. AEA1 experimental [61, 63]. AEA2 experimental [37], [80]

Introduced the electronic correlation effects with PBE functional and the relativistic effects SDD has been obtained, for the adiabatic electronic affinitie, value very nears of the experimental data reported in $[62-64,48]$ for $A g_{n}(\mathrm{n}=1-4)$ (see Fig. 44 and 45). With the electronic correlation effects $\mathrm{PBE} / 3-21 \mathrm{G}^{* *}$, the values are very distant of the experimental data, see Fig. 46 and 47.

With B3LYP functional and LANL2DZ has been obtained good results for the adiabatic electronic affinity, Fig. 46 and
47.

The results obtained in this work for the silver cluster optimized with MP2/LANL2DZ concured with the results in the literature employed MP2 and LANL2DZ [65].

If compared the results obtained with $\mathrm{DFT} / \mathrm{PBE} / \mathrm{SDD}$, DFT/PBE/3-21G** and HF/LANL2DZ the relativistic effects only, are not much influenced in adiabatic electronic affinity and neither the electronic correlation effects with PBE functional.

Analyzed the date obtained with DFT/B3LYP/LANL2DZ and DFT/PBE/SDD I see little variation.

\subsection{Vertical and Adiabatic Ionization Potential}

The adiabatic ionization potential are defined how the energy of transitionin origin beteen the basal state of cation and the basal state of neutral with $I=E_{n}^{+}-E_{n}$., where $E_{n}^{+}$is the total energie of species of cations after optimization the structure and $E_{n}$ is the total species neutral optimizated [25].

Tendency of the clusters optained with HF, see Fig. 45 and 46 is do not equal with the experimental date [66,18]. The values of ionization potential are extensive comparable with electronic affinity [27, 67].

With LANL1MB and LANL2MB change of the dates for dimer and trimer clusters are the same.

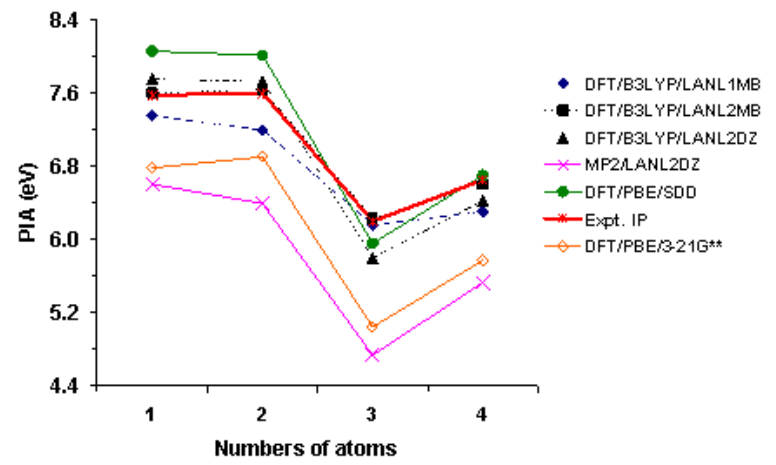

Fig. 48. Adiabatic electronic potential for silver cluster employed DFT. Vs. Number of atoms in the cluster:Experimental potential of ionization [6, 46], [80]

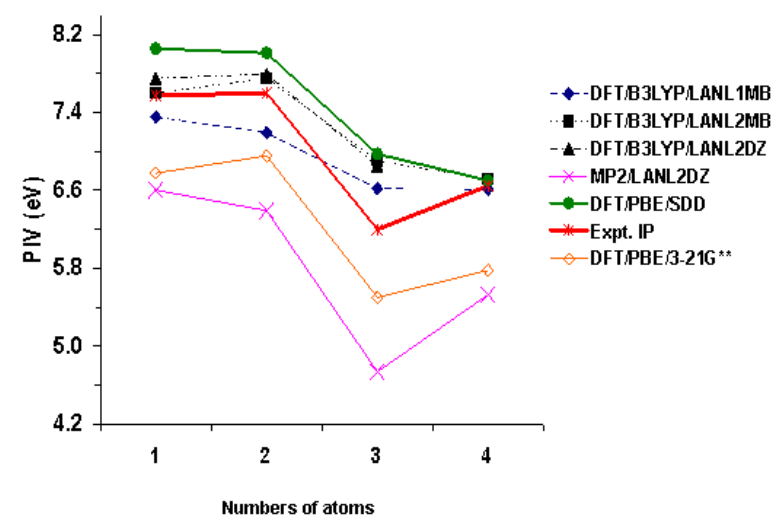

Fig. 49. Adiabatic electronic potential for silver cluster employed DFT. Vs. Number of atoms in the cluster.Experimental potential of ionization [6, 46], [80] 


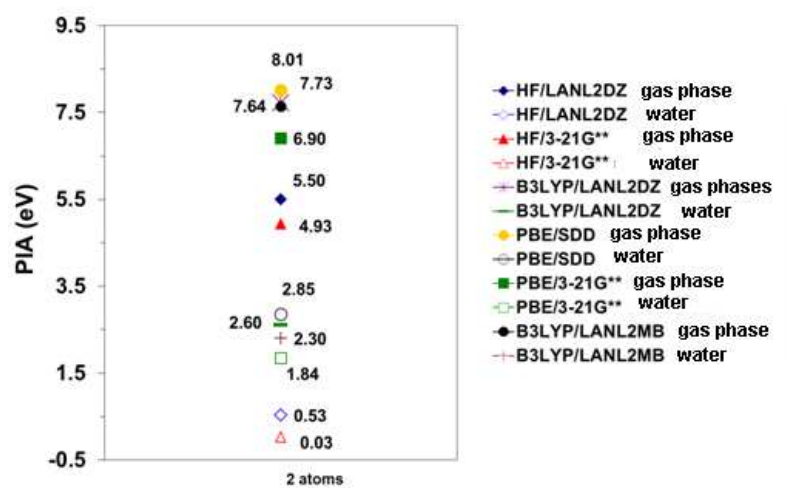

Fig. 50. Adiabatic electronic potential for silver dimer cluster in water and gas phase. The graphics is change

With see the Fig 48 has been optained good results when are employed B3LYP/LANL2MB. The diference with experimental data are de $0.03 \mathrm{eV}$ for one atom, two atoms and three atoms and, $0.14 \mathrm{eV}$ for fourth atoms clusters.

When are employed B3LYP/LANL2DZ level of theorie are obtained $7.75 \mathrm{eV}$ estimated with $7.57 \mathrm{eV}$, the experimental data for one atom, $7.72 \mathrm{eV}$ compared with 7.6 $\mathrm{eV}$, the experimental data for two atoms, see Fig.49.

The better result are optained with B3LYP and are near of the jellium model (SJBM). Are better PBE/SDD who PBE/3$21 \mathrm{G}^{* *}$.

The electron are ionizated of the feeble biding orbital, see Fig 48 and 49. The IP for three atoms are less who for over.

\section{Frecuencies}

How see in Table 1 the values better near of the experimental data for two atoms anion and catión has been obtained employed PBE/SDD. For neutral dimer employed $\mathrm{PBE} / 3-21 \mathrm{G}^{* *}$ are optained $199.08 \mathrm{~cm}^{-1}$ forehead to $192.4(5)$, the experimental data (see Table 1) continued for the DFT/PBE/SDD level.

Tabla 1. The armonic frecuencia (in $\mathrm{cm}^{-1}$ ) of the mas stable silver clusters.

\begin{tabular}{|c|c|c|c|c|c|}
\hline $\mathrm{Ag}_{4}$ & $\mathrm{Ag}_{4}^{-}$ & $\mathrm{Ag}_{4}^{+}$ & $\mathbf{A g}_{3}$ & $\mathrm{Ag}_{3}^{-}$ & $\mathrm{Ag}_{3}^{+}$ \\
\hline & & & $\begin{array}{l}161.1 \\
(157.9)^{\mathrm{a}}\end{array}$ & & \\
\hline $34.16^{\mathrm{b}}$ & $71.57^{\mathrm{b}}$ & $15.56^{\mathrm{b}}$ & $13.25^{\mathrm{b}}$ & $28.44^{\mathrm{b}}$ & $110.80^{b}$ \\
\hline $71.58^{b}$ & $134.57^{b}$ & $71.32^{\mathrm{b}}$ & $112.71^{\mathrm{b}}$ & $89.96^{\mathrm{b}}$ & $110.89^{b}$ \\
\hline $76.25^{\mathrm{b}}$ & $166.53^{b}$ & $84.80^{\mathrm{b}}$ & $159.16^{\mathrm{b}}$ & $156.12^{b}$ & $167.53^{b}$ \\
\hline $100.30^{\mathrm{b}}$ & & $87.45^{\mathrm{b}}$ & & & \\
\hline $152.35^{\mathrm{b}}$ & & $127.64^{b}$ & & & \\
\hline $174.99^{\mathrm{b}}$ & & $160.11^{b}$ & & & \\
\hline $38.44^{c}$ & $15.23^{c}$ & $18.44^{\mathrm{c}}$ & $11.79^{c}$ & $34.94^{\mathrm{c}}$ & $117.87^{c}$ \\
\hline $82.89^{c}$ & $22.95^{c}$ & $82.03^{c}$ & $126.41^{c}$ & $107.76^{c}$ & $118.49^{c}$ \\
\hline $186.73^{c}$ & $28.65^{\mathrm{c}}$ & $94.76^{\mathrm{c}}$ & $171.33^{c}$ & $178.23^{c}$ & $174.66^{\mathrm{c}}$ \\
\hline $92.77^{\mathrm{c}}$ & $78.31^{\mathrm{c}}$ & $103.86^{\mathrm{c}}$ & & & \\
\hline $164.57^{\mathrm{c}}$ & $144.02^{\mathrm{c}}$ & $146.94^{c}$ & & & \\
\hline \multirow[t]{7}{*}{$186.73^{\mathrm{c}}$} & $178.47^{\mathrm{c}}$ & $169.87^{\mathrm{c}}$ & & & \\
\hline & & $14.87^{\mathrm{d}}$ & $87.72^{\mathrm{d}}$ & $42.97^{\mathrm{d}}$ & $118.71^{\mathrm{d}}$ \\
\hline & & $91.02^{\mathrm{d}}$ & $114.58^{\mathrm{d}}$ & $128.23^{d}$ & $118.71^{d}$ \\
\hline & & $97.31^{\mathrm{d}}$ & $197.20^{d}$ & $196.12^{d}$ & $184.06^{\mathrm{d}}$ \\
\hline & & $115.05^{\mathrm{d}}$ & $5.63^{\mathrm{e}}$ & & \\
\hline & & $158.53^{d}$ & $80.55^{\mathrm{e}}$ & & \\
\hline & & $178.05^{\mathrm{d}}$ & $91.70^{\mathrm{e}}$ & & \\
\hline
\end{tabular}

${ }^{\mathrm{a}}$ experimental data $[29]^{\mathrm{b}}$ the date of the present worck with DFT/B3LYP/LANL2DZ level of theorie

${ }^{c}$ the date of present worck with DFT/PBE/SDD d the date of the present worck with DFT/PBE/3-21G** level of theorie ${ }^{e}$ the date of presen worck withl HF/LANL2DZ

Tabla 2. Energy, adiabatic electronic potential, adiabatic electronic afinityof the clusterin solvent ( $\varepsilon=78.39)$. Are employed PCM.

\begin{tabular}{|c|c|c|c|c|c|c|}
\hline No. atoms & Method & $\mathbf{E}_{\mathbf{T}}$ & $\mathbf{E}_{\text {cat }}$ & $\mathbf{E}_{\text {anion }}$ & $\mathbf{I}_{\text {adiab }}$ & $\mathbf{A} \mathbf{E}_{\text {adiab }}$ \\
\hline & $\operatorname{PCM}(\varepsilon=78.39)$ & & & & & \\
\hline 1 & $\mathrm{DFT} / \mathrm{PBE} / 3-21 \mathrm{G}^{* *}$ & 140839.45 & -140837.14 & -140841.38 & 2.31 & 1.93 \\
\hline 2 & & -281681.21 & -281678.06 & -281682.42 & 3.14 & 1.21 \\
\hline 1 & DFT/PBE//SDD & -3998.80 & -3995.52 & -4001.71 & 3.28 & 3.75 \\
\hline 2 & & -7999.42 & -7995.27 & -8001.47 & 4.52 & \\
\hline 1 & $\begin{array}{l}\text { DFT/B3LYP/ } \\
\text { LANL2DZ }\end{array}$ & -3966.45 & -3963.38 & -3969.20 & 1.77 & 2.75 \\
\hline 2 & & -7934.50 & -7930.60 & -7936.41 & 2.60 & 1.91 \\
\hline 1 & $\begin{array}{l}\text { DFT/B3LYP/ } \\
\text { LANL2MB }\end{array}$ & -3966.31 & -3963.37 & -3968.84 & 2.94 & 2.53 \\
\hline 2 & & -7933.79 & -7930.19 & -7935.62 & 3.60 & 1.83 \\
\hline 1 & $\mathrm{HF} / 3-21 \mathrm{G}^{* *}$ & -140786.77 & -140785.52 & -140787.28 & 1.25 & 0.51 \\
\hline 2 & & -281574.21 & -281572.89 & -281574.63 & 1.33 & 0.41 \\
\hline 1 & HF/LANL2DZ & -3942.88 & -39.41 .179 & -3943.91 & 1.70 & 1.04 \\
\hline 2 & & -7886.22 & -7884.39 & -7887.12 & 1.83 & 0.89 \\
\hline
\end{tabular}

$\mathrm{E}_{\mathrm{T}}$ - total energy of $\mathrm{Ag}_{1}$ y $\mathrm{Ag}_{2}$

$\mathrm{E}_{\text {cat }}$ energy of $\mathrm{Ag}_{1}$ y $\mathrm{Ag}_{2}$ cation

$\mathrm{E}_{\text {anion }}$ - energyof $\mathrm{Ag}_{1}$ y $\mathrm{Ag}_{2}$ anion

$\mathrm{I}_{\text {adiab}}$-adiabatic potential for $\mathrm{Ag}_{1}$ and $\mathrm{Ag}_{2}$

$\mathrm{AE}_{\text {adiab}}$-adiabatic afinity for $\mathrm{Ag}_{1}$ and $\mathrm{Ag}_{2}$ 
In the Table 3 are see the anion dimer optained with $\mathrm{PBE} / \mathrm{SDD}$ and HF/LANL2DZ

Tabla 3. The armonic frecuencia (in $\mathrm{cm}^{-1}$ ) of the mas stable silver clusters in gas phase, [80]

\begin{tabular}{llll}
\hline Métodos & $\mathbf{A g}_{2}$ & $\mathrm{Ag}_{2}^{-}$ & $\mathrm{Ag}_{2}^{+}$ \\
\hline Experimental[20,21] & $192.4(5)^{\mathrm{a}, \mathrm{b}}$ & $145.0^{\mathrm{c}}$ & $135.8^{\mathrm{c}}$ \\
DFT/PBE/3-21G** & 199.07 & 165.96 & 141.13 \\
DFT/PBE/SDD & 185.94 & 134.22 & 131.58 \\
DFT/B3LYP/LANL2DZ & 177.06 & 125.61 & 124.16 \\
DFT/B3LYP/LANL2MB & 146.45 & 125.61 & 124.16 \\
HF/3-21G** & 141.12 & 97.26 & 94.48 \\
HF/LANL2DZ & 149.32 & 88.59 & 91.30 \\
\hline
\end{tabular}

a experimental [28]

${ }^{\mathrm{b}}$ experimental [29]

${ }^{c}$ experimental [30]

Tabla 4. The frecuencies obtained for the silver cluster in acuos solution with the PCM $(\varepsilon=78.39)$ model.

\begin{tabular}{llll}
\hline $\begin{array}{l}\text { MÉTODOS } \\
\text { solvatación }(\boldsymbol{\varepsilon}=\mathbf{7 8 . 3 9})\end{array}$ & $\mathbf{A g}_{2}$ & $\mathrm{Ag}_{2}^{-}$ & $\mathrm{Ag}_{2}^{+}$ \\
\hline DFT/PBE/3-21G** & 188.15 & 120.1191 & 157.79 \\
DFT/PBE/SDD & 175.53 & -53.28 & 138.12 \\
DFT/B3LYP/LANL2DZ & 162.00 & 94.47 & 133.35 \\
DFT/B3LYP/LANL2MB & 146.45 & 94.47 & 133.35 \\
HF/3-21G** & 111.75 & 46.23 & 95.51 \\
HF/LANL2DZ & 115.76 & -17.85 & 85.39 \\
\hline
\end{tabular}

Tabla 5. The values of HOMO, LUMO, and gap for the Ag2 clusters in the gas phase.[80]

\begin{tabular}{llll}
\hline Method & HOMO $(\mathrm{eV})$ & $\begin{array}{l}\text { LUMO } \\
(\mathbf{e V})\end{array}$ & $\begin{array}{l}\text { HOMO-LUMO } \\
\text { gap }(\mathrm{eV})\end{array}$ \\
\hline DFT/PBE/3-21G** & -4.290 & -2.379 & 1.911 \\
DFT/PBE//SDD & -5.262 & -3.235 & 2.027 \\
DFT/B3LYP/LANL2DZ & -5.558 & -2.653 & 2.905 \\
DFT/B3LYP/LANL2MB & -5.559 & -2.845 & 2.714 \\
HF/3-21G** & -5.392 & 0.253 & 5.139 \\
HF/LANL2DZ & -5.949 & 0.030 & 5.979 \\
\hline
\end{tabular}

Tabla 6. Values of HOMO, LUMO, and gap for the $\mathrm{Ag}_{2}$ clusters obtained in acuos solution employed PCM model with $\varepsilon=78.39$.

\begin{tabular}{|c|c|c|c|}
\hline \multicolumn{4}{|c|}{ SOLVATATION $(\varepsilon=78.39)$} \\
\hline Method & HOMO (eV) & $\begin{array}{l}\begin{array}{l}\text { LUMO } \\
\text { (eV) }\end{array} \\
\end{array}$ & $\begin{array}{l}\text { HOMO-LUMO } \\
\text { gap }(\mathrm{eV})\end{array}$ \\
\hline DFT/PBE/3-21G** & -3.230 & -1.021 & 2.209 \\
\hline $\mathrm{DFT} / \mathrm{PBE} / / \mathrm{SDD}$ & -4.230 & -1.836 & 2.394 \\
\hline DFT/B3LYP/LANL2DZ & -4.572 & -1.276 & 3.295 \\
\hline DFT/B3LYP/LANL2MB & -4.170 & -1.259 & 2.912 \\
\hline $\mathrm{HF} / 3-21 \mathrm{G}^{* *}$ & -4.300 & 1.682 & 2.618 \\
\hline HF/LANL2DZ & -5.175 & 1.217 & 3.958 \\
\hline
\end{tabular}

Tabla 7. Values of HOMO, LUMO, and gap for the $\mathrm{Ag}_{3}$ clusters obtained in the gas phase.[80]

\begin{tabular}{llll}
\hline Method & HOMO $(\mathrm{eV})$ & $\begin{array}{l}\text { LUMO } \\
(\mathbf{e V})\end{array}$ & $\begin{array}{l}\text { HOMO-LUMO } \\
\text { gap }(\mathbf{e V})\end{array}$ \\
\hline DFT/PBE/3-21G** & -4.129 & -2.814 & 1.314 \\
DFT/PBE//SDD & -5.136 & -3.600 & 1.536 \\
DFT/B3LYP/LANL2DZ & -5.419 & -3.039 & 2.380 \\
DFT/B3LYP/LANL2MB & -5.411 & -3.164 & 2.247 \\
HF/3-21G** & -5.045 & -3.164 & 1.881 \\
HF/LANL2DZ & -5.354 & -3.164 & 2.190 \\
\hline
\end{tabular}

Tabla 8. Values of HOMO, LUMO, and gap for the $\mathrm{Ag}_{3}$ clusters obtained in the solvent.

\begin{tabular}{llll}
\hline \multicolumn{2}{l}{ SOLVATACIÓN $(\varepsilon=78.39)$} & & \\
\hline Métodos & HOMO $(\mathbf{e V})$ & $\begin{array}{l}\text { LUMO } \\
(\mathbf{e V})\end{array}$ & $\begin{array}{l}\text { HOMO-LUMO } \\
\text { gap }(\mathbf{e V})\end{array}$ \\
\hline DFT/PBE/3-21G** & -2.284 & -1.268 & 1.576 \\
DFT/PBE//SDD & -5.136 & -3.600 & 1.536 \\
DFT/B3LYP/LANL2DZ & -4.045 & -1.463 & 2.582 \\
DFT/B3LYP/LANL2MB & -5.411 & -3.164 & 2.247 \\
DFT/B3LYP/LANL1MB & -3.268 & -1.178 & 2.090 \\
HF/3-21G** & -5.354 & 0.028 & 5.382 \\
\hline
\end{tabular}

\section{Hardness}

Are calculated hardness with the objective see the reactivity of the cluster taken in account the relativistic effects and electronic correlation and see what silver cluster digest how soft acid $r$ soft base $u$ hard acid or hard base. The value of hardnees ar in Fig. 51 and52. And are employed $\eta=$ (I-A) $/ 2$.

With the HF I observ who the more reactive are the structure with for atoms.

When I empolyed LANL1MB the $1.64 \mathrm{eV}$ are obtained, for the LANL2DZ level the value are $1.70 \mathrm{eV}$, see Fig.51.

To be observed who the reactivity increment with el namber of atoms in the cluster and not exist the variation pair unequal. The $\mathrm{Ag}_{3}$ optimised with HF/LANL2DZ is near of the experimental hardness.

See de hardness experimental in Fig. 42, 50 and 47 [62, 64 $68,66,18]$.

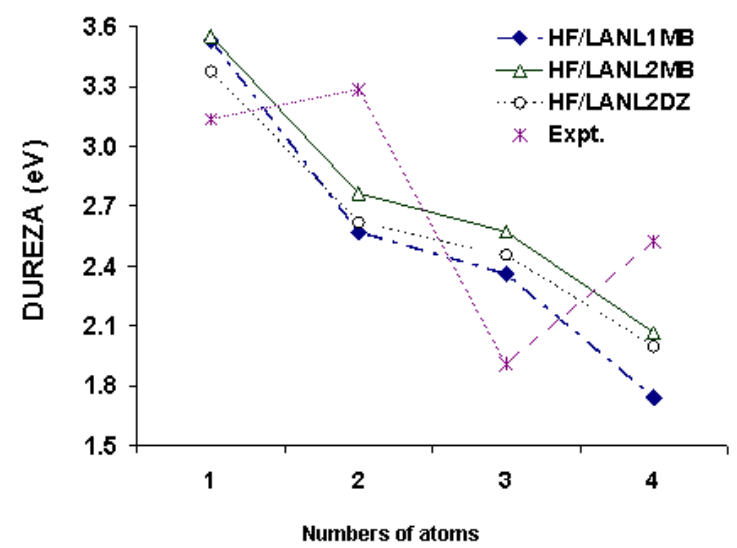

Fig. 51. Hardness ( $\eta$ ) for the silver clusters employed HF. Vs. Number of the atoms in the cluster. , [80] 


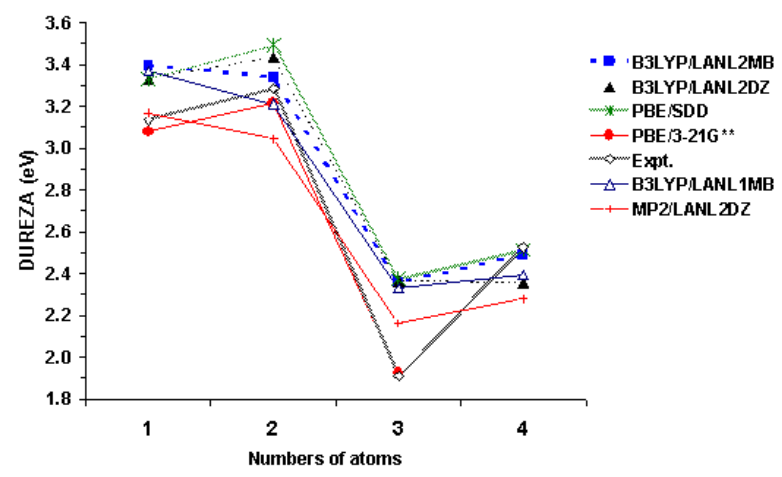

Fig. 52. Hardness ( $\eta$ ) for the silver clusters employed DFT. Vs. Number of the atoms in the cluster. [80]

In the Fig.51 I see the best reactive are three atoms and for atoms.

Inthe Table 7 and 8 are the value obtained for the difference HOMO-LUMO (gap) for the clusters employed the Klopman theorie.[68].

Are calculated the HOMO-LUMO with:

$$
\text { HOMO-LUMO }=\left(-\mathrm{E}_{\text {Hомо }}\right)-\left(-\mathrm{E}_{\text {LUMO }}\right)
$$

$\mathrm{E}_{\mathrm{HOMO}}=$ theenergie of the orbital high occupied

$\mathrm{E}_{\mathrm{LUMO}}=$ the energie of the orbitallow occupied.

The value optained in the gas phase are smaller in 0.2-0.3 $\mathrm{eV}$ nearly with respect of the values in aqueous solution, it who oppose who the solvent make that increase the difference HOMO-LUMO.

With HF/LANLEDZ and HF/3-21G* has been obtained less values of gap with 2.521 and $2.021 \mathrm{eV}$ who in gas phase.

In the water the values are different and are not experimental data.

\section{Conclusions}

Introducing the electronic correlation effects without reelativistic effect with the PBE functional and the $3-21 \mathrm{G}^{* *}$ has been optained the best results of $2.53 \AA$, compared with PBE/SDD with wichhas been obtained 2,57 $\AA$ for neutral dimer.

Of where has been concluid who the electronic correlation effects modify more in the distance beteen the clusters thwt the relativist effects.

The anion clusters almost all case are the lineal form how the most stable, the cation of equilateral triangle and isosceles.

At make additions un electron the clusters of two and for atoms optimized with HF are better stable what of the three atoms, in barter for the cation cluster at remove un electron perform who the cluster with pair number are less stable who the cluster with unequalnumber.

Not be able make the same for the clusters optimized introduce the electronic correlation, in this case the charge are uniformly disposed beteen the three atoms in the lineal form.
Introduced the density funtional are incluyed in B3LYP the LDA funtional it who make what the result obtained with DFT/B3LYP/LANL2MB it be more near of the experimental data, respecting the model of jellium layer.

In this case I observed who the relativistic effects not influence in the proprieties how the lectronic affinity and ionization potential. Compared PBE/3-21G** and PBE/SDD the electronic correlation are complementary wiht the relativistic effect. The MP2 are improper with the electronic afinity and ionization potential.

The results obtaine with PBE/3-21G** and PBE/SDD for the frecuencies are the near of the experimentals date.

The values of the hardness are near of the experimentals data hav been obtained for $\mathrm{PBE} / 3-21 \mathrm{G}^{* *}$ following for $\mathrm{PBE} / \mathrm{SDD}$, whey the electronic correletion are important compiting with the tow effects the relativistic with electronic correlation. The dipole of wáter are influenced the prorieties of cluster.

\section{References}

[1] Huda M.N.; Ray A. K.; Phys. Rev. A, 2003, 67, 013210.

[2] Fournier R., J. Chem. Phys., 2001, 2165.

[3] Wnag B.; Chen X.; Wang J.; Zhao J., Surface Review and Letters, 2004, 11,15.

[4] Monti O.L.A.; Fourkas, J.T.;Nesbitt D.J., J. Phys. Chem. B, 2004, 108, 1604.

[5] Zhang L.; Yuu J.C., Ho Yin Yip; Li Q.; Kwong K. W.; Xu A. Wu; Wong Po K.; Langmuir, 2003, 19, 10372.

[6] Yuranava T.; Rincon A.G.; Bozzi A.G.; Parra S.; Pulgarin C.; Albers P.; Kiwi J., J. Photochem, Photobiol.A., 2003, 161, 27.

[7] Empedocles; Neuhauser R.; Shimizu K.; Bawendi M.G., Adv. Mater., 1999, 11, 1243.

[8] Link S.; El-Sayed , Int Rev. Phys. Chem., 2000, 19, 409.

[9] Andersen P.C.; Rowlen K.L., Appl. Spectroscop., 2002, 56, $124 \mathrm{~A}$.

[10] Henglein A., Chem. Rev. 1989, 89, 1861.

[11] Kim S.H.; Ribeiro G.M.; Ohlberg D.A.A.; Williams R.S., Heath J.R., J.Phys. Chem., 1999, 103, 10341.

[12] Zuhuang J., Bactericidal nanosilver cloth and its making proces and use. Patent number CN 1387700, 2003.

[13] Chen C.M.S., Process for preparing antibacterial antimildew polyacrylic fibers and its filter net for air condiyioner. Patent number CN 1355335, 2003.

[14] Lee H.J.; Yeo .S.Y.; Jeong, J. Mat. Sci., 2003,38, 2199.

[15] Balasubramanian K., J. Phys. Chem., 1989, 93, 6585.

[16] Ichihara K.T.; Fujita Y.;Matsuo T., Sakuray T.; Matsuda H., Int. J. Mass, Spectrom. In. Proc., 1985, 67, 229; ibid. 1986, 74, 33.

[17] Handschuh H.; Cha C.Y.; Bechthold P.S.; Ganteför, Eberhatdt W., J. Chem. Phys., 1995, 102, 6406. 
[18] Haslett T.L.; Bosnick K.A.; Fedrigo S.; Moskovits M., J. Chem. 1999, 11, 14, 6456,

[19] Wedum E.E.; Grant E.R.; Cheng P.Y.; Willy K.F.; Duncan M.A., J. Chem. Phys. Lett., 1991, 100, 6312.

[20] Félix C.; Sieber C.; Harbich W.; Buttet J.; Rabin I.; Schultze W. Ertl, Chem. Phys. Lett., 1999, 313, 195.

[21] Howard J.A.; Sutcliffe R.; Mile B., Surf. Sci., 1985, 156, 214.

[22] Haslett T.L.; Bosnick K.A.; Moskovits M., J. Chem. Phys., 1998, 108, 3453.

[23] Rabin I.; Jackschath C.; Schultze W., Z. Phys. D, 1991, 19, 153. Jackschath, Rabin I.; Schultze W., ibid, 1992, 22, 517.

[24] Allameddin G.; Hunter J., Cameron D.; Kappes M.M., Chem. Phys. Lett, 1992, 192, 122.

[25] Ho J.; Ervin K.M.; Lineberger, J. Chem. Phys. 1990, 93, 6987.

[26] Leopold, D.G.; Ho J.; Leneberger W.C., J. Chem. Phys., 1987, $86,1715$.

[27] Taylor K.J., Pettiette-Hall C.L.; Cheshnovsky O.; Smalley, J. Chem. Phys., 1992, 96, 3319.

[28] Handuschu H.; Chaa C. Y.; Bechtold P.S., Ganteför G.; Eberhatdt, J. Chem. Phys., 1995, 102, 6406.

[29] Okazaki T.; Saito Y., Kasuya A., Nishina Y., J. Chem. Phys., 1996, 104, 812.

[30] Tiggesbäumeker T.; Köller L., Meiwes-Broer K.; Liebesch A., Phys. Rev. A, 1993, 48, 1749.

[31] Minemoto, Iseda M., Kondow T., Eur. Phys. J.D., 1999, 9, 163.

[32] Bonačič Koutecký V.; Češpiva; Fantucci P.; Pittner J.; Koutecký J., J. Chem. Phys., 1994, 100, 1.

[33] Santamaria R.; Kaplan I. G.; Novaro O.; Chem. Phys. Letters, 1994, 218, 395.

[34] Liu Z.F.; Yim W.L.; Tse J.S.; Hafner J., Eur. Phys. J.D., 2000, 10,105 .

[35] Zhao J.; Luo Y.; Wang Eur. Phys., J. D, 2001, 14, 309.

[36] Legge Sue F., Nyberg Graeme L., Peel Barrie J., J. Phys. Chem A, 2001, 105, 7905.

[37] Weis P.; Bierweiler T.; Gilb S.; Kappes M.M., Chem Phys. Lett., 2002, 355, 355.

[38] Mitrić, Hartmann M.; Stanca B.; Bonačič Koutecký V.; Fantucci, J. Phys. Chem., 2001, A 105, 8892.

[39] Poteau R.; Heully J.L.; Spiegelman F.; Z. Phys. D, 1997, 49, 479.

[40] Tian Z.M., Tian Y.; Wei W.M.; He T.J.; Chen D.M.; Liu F.C., Chem. Phis. Lett, 2006, 420, 450.

[41] Wedum E.E., Grant E.R., Chang P.Y.; Willey K.F.; Duncan M.A., J. Chem. Phys., 1994,100.

[42] Cheng P.Y.; Duncan M.A., Chem Phys. Lett., 1988, 152, 341.

[43] Ellis M.; Robles E.S.J., Millar I.A., Chem Phys. Letter.,1993, 201132.

[44] Bonačič Koutecký V.; Veyeret V.; Mitric R., J. Chem. Phys.,
$2001,115,10450$.

[45] Hay P.J.; Wadt W.R., J. Chem. Phys., 1985, 82, 284.

[46] Hay P.J.; Wadt W.R., J. Chem. Phys., 1985, 82, 299.

[47] Boo D. Wan; Ozaki Y.; Andersen L. H.; Lineberger W.C., J. Phys. Chem A., 1997, 101, 6688.

[48] Ho J.; Ervin K.M., Lienberger W.C., J. Chem. Phys. 1990, 93, 6987.

[49] Bagatur'yants A.A.; Safanov A.A., Stoll H.; Werner H.J., J. Chem. Phys., 1998, 109, 3096.

[50] Boo Wan D., Ozaki Y., Andersen L. H.; Lineberger W.C., J. Phys. Chem A., 1997, 101, 6688.

[51] Schultze W.; Becker H.U.; Minkwitz R.; Mansel K., Chem. Phys. Letters, 1978, 55, 59.

[52] Moskowits M., DiLella D.P., J. Chem. Phys., 1980, 72, 2267.

[53] Joward J.A.; Preston K.F.; J. Am. Chem. Soc. 1981, 103, 6226.

[54] Kernisant K., Thompson G.A., Lindsay D.M., J. Chem. Phys., $1985,82,4739$.

[55] Morse M.D., Chem. Rev. 1986, 86, 1049.

[56] Bonačić-Koutecký V.; Češpiva L., J. Chem. Phys., 1993, 98, 7981.

[57] Basch H., J. Am. Chem. Soc., 1981, 103, 4657.

[58] Matulis V.E; Ivashkevich O.A.; Gurin V.S, J. Molec. Struct. (Theochem), 2003, 664-665, 291.

[59] Häkkinen H.; Moseler M.; Landman Uzi, Physical Rev. Lett., 2002, 89, 033401-1.

[60] Huda M.N.; Ray A.K., Eur. Phys. J. D, 2003, 22, 217.

[61] Boo Wan D.; Ozaki Y, Andersen L. H.; Lineberger W.C, J. Phys. Chem A., 1997, 101, 6688.

[62] Spasov V.A., Lee T.H. ; Maberry J.P. ; Ervin K.M., J. Chem. Phys., 1999, 110, 5208,

[63] Shi Y., Spasov V.A., Ervin K.M., J. Chem. Phys., 1999, 111, 938.

[64] Moore C.E., Atomic energy levels, NSRDS-NBS Circular No. 467, USGPO, Washington, 1949.

[65] Zuhuang J., Bactericidal nano-silver cloth and its making process and use. Patent number CN 1387700, 2003.

[66] Rabin I., Jackschath C.; Schulze W., Z. Phys. D, 1991, 19, 153,. Jackschath C., Rabin I.; Schulze W., ibid. 1992, 22, 517.

[67] Ekardt W., Phys. Rev. B, 1984, 29, 1558.

[68] C.E. Moore, Atomic energy levels, NSRDS-NBS Circular No. 467, USGPO, Washington, 1949.

[69] Foresman J.B., Frisch A., Gaussian, Inc. Pittsburgh, PA, 230249, 1996.

[70] I. Rabin, W. Schultze, G. Ertl, Chemical Physics Letters, 312, 394-398, 1999.

[71] I. Rabin , W. Schulze, G. Ertl, C. Felix, C. Sieber, W. Harbich, J. Buttet, Chemical Physics Letters, 320, 59-64, 2000. 
[72] E.C. Cosgriff, C.T. Chantler, C. Witte, L.F. Smale, C.Q. Tran, Physics Letters A, 343, 174-180, 2005.

[73] S. Fedrigo, W. Harbich, and J. Buttet, Physical Review B, 47(16), 10706-10715, 1993.

[74] George Alameddin, Joanna Hunter, Douglas Cameron and Manfred M. Kappes, Chemical Physics Letters, 192(1), 123128, 1992.

[75] H. Handschuh, Chia-Yen Cha, P. S. Bechthold, G. Ganteför, and W. Eberhardt, J.Chem. Phys., 102(16), 6406-6422, 1995.

[76] I. Katakuse, T. Ichijara, International Journal of Mass Spectrometry and Ion Processes, 74, 33-41, 1986.
[77] W. Schulze, H. Becker, R. Minikwitz, K. Manzel, Chemical Physics Letters, 55 (1), 59-61, 1978.

[78] Joe Ho, Kent M. Ervin, W.C. Lineberger, J. Chem. Phys., 93 (10), 6987-7002, 1990.

[79] G. V. Krylova, A. M. Eremenko, N. P. Smirnova, S. Eustis, Theoretical and Experimental Chemistry, 41 (2), 2005.

[80] M.Virginia Popa, International Journal of Computational and Theoretical Chemistry online, 2 (6), 46-68. 